\title{
Androgen receptor promotes renal cell carcinoma (RCC) vasculogenic mimicry (VM) via altering TWIST1 nonsense-mediated decay through IncRNA-TANAR
}

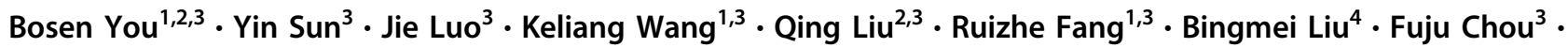

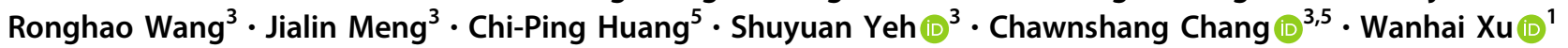

Received: 2 July 2020 / Revised: 30 November 2020 / Accepted: 10 December 2020 / Published online: 28 January 2021

(c) The Author(s), under exclusive licence to Springer Nature Limited 2021. This article is published with open access

\begin{abstract}
While the androgen receptor (AR) may influence the progression of clear cell renal cell carcinoma (ccRCC), its role to impact vasculogenic mimicry (VM) to alter the ccRCC progression and metastasis remains obscure. Here, we demonstrated that elevated AR expression was positively correlated with tumor-originated vasculogenesis in ccRCC patients. Consistently, in vitro research revealed AR promoted VM formation in ccRCC cell lines via modulating lncRNA-TANAR/ TWIST1 signals. Mechanism dissection showed that AR could increase lncRNA-TANAR (TANAR) expression through binding to the androgen response elements (AREs) located in its promoter region. Moreover, we found that TANAR could impede nonsense-mediated mRNA decay (NMD) of TWIST1 mRNA by direct interaction with TWIST1 $5^{\prime} \mathrm{UTR}$. A preclinical study using in vivo mouse model with orthotopic xenografts of ccRCC cells further confirmed the in vitro data. Together, these results illustrated that AR-mediated TANAR signals might play a crucial role in ccRCC VM formation and metastasis, and targeting this newly identified AR/TANAR/TWIST1 signaling may help in the development of a novel antiangiogenesis therapy to better suppress the ccRCC progression.
\end{abstract}

These authors contributed equally: Bosen You, Yin Sun, Jie Luo, Keliang Wang

Supplementary information The online version of this article (https:// doi.org/10.1038/s41388-020-01616-1) contains supplementary material, which is available to authorized users.

Chawnshang Chang

chang@urmc.rochester.edu

$\triangle$ Wanhai Xu

xuwanhai@hrbmu.edu.cn

1 Department of Urology, The 4th Affiliated Hospital of Harbin Medical University, Harbin 150001, China

2 Department of Urology, The 2nd Affiliated Hospital of Harbin Medical University, Harbin 150001, China

3 George Whipple Lab for Cancer Research, Departments of Pathology and Urology, and The Wilmot Cancer Institute, University of Rochester Medical Center, Rochester, NY 14646, USA

4 Department of Pathology and Cutaneous Oncology, Heilongjiang Provincial Hospital, Harbin 150001, China

5 Sex Hormone Research Center and Departments of Urology, China Medical University/Hospital, Taichung 404, Taiwan

\section{Introduction}

Clear cell renal cell carcinoma (ccRCC), the major subtype of aggressive human malignancies, accounted for approximately $1,000,000$ cases and 175,000 deaths worldwide in 2018 [1]. Despite the shift towards early stages at diagnosis, fatal metastasis, or rapid recurrence occurred in $1 / 3$ to $1 / 4$ of cases [2]. For most metastatic RCC, anti-angiogenesis therapy, such as treatment with sunitinib and pazopanib, as well as with vascular endothelial growth factor receptor tyrosine kinase inhibitor (TKI), has proved its efficacy. However, the vast majority of patients will ultimately acquire resistance and relapse, and some patients are inherently refractory to the targeted therapy $[3,4]$. Hence, the detailed mechanisms of RCC progression and angiogenesis need to be comprehensively understood for the development of better efficacies.

The androgen receptor (AR) can promote progression and hematogenous metastasis in ccRCC through ASS1P3/ miR-34a-5p/ASS1 and miR-185-5p/HIF-2a/VEGF signaling, respectively $[5,6]$. This is consistent with the higher incidence and more malignant phenotypes in males according to data from the surveillance epidemiology and 
end results database [7]. Furthermore, targeting AR with the antiandrogen enzalutamide (Enz) could restore sunitinib sensitivity in the sunitinib-resistant PDX mouse model, suggesting enhancing TKI efficacy through inhibition of AR to better suppress ccRCC progression [8]. Paradoxically, a higher expression of AR is associated with better prognosis based on a retrospective analysis from the TCGA database, indicating that AR function in ccRCC is complex and may be tumor stage-dependent [9].

Besides the classical tumor angiogenesis, Maniotis et al. demonstrated a de novo pattern of tumor perfusion in melanomas, named vasculogenic mimicry (VM), in which cancer cells form their own supplying channel without endothelial cells [10]. Due to its ability to circulate blood from vessels to tumor tissues and to facilitate tumor cells into the extracellular matrix, VM plays a significant role in boosting tumor growth as well as promoting metastasis, which contributes to poor prognosis and aggressiveness in many cancers [11-16]. On the other hand, as an alternative nutrient supplement, VM complements the cancer vasculature theory and provides a mechanistic alternative for the inherently or acquired resistance to anti-angiogenesis therapy [17]. Periodic acid Schiff (PAS) staining and CD31 (or CD34) immunohistochemistry (IHC) have been widely used to identify VM formation in vivo [10]. In addition to Matrigel architecture, a novel collagen-induced migration program of VM, characterized by short fibers and small pores provides another in vitro assay to mimic the VM formation in vivo [18]. Although this unique vascular channel formation was first reported in kidney cancer in 2013 [19], to date the VM molecular pathway in RCC still remains poorly understood.

Long noncoding RNAs (lncRNAs), a class of untranslated transcripts longer than 200 nucleotides barely with protein-coding capacity, participate in diverse biological processes [20]. Mounting evidence has proved lncRNAs significantly influence the pathogenesis of cancers via transcriptional regulation or direct interaction with miRNAs, mRNAs, and proteins in a multitude of molecular pathways [21]. Recently, IncRNAs have been shown to also modulate genitourinary malignancies via different pathways including proliferation, apoptosis, angiogenesis, and drug resistance. However, little is known about the potential role of IncRNAs involved in VM formation [4, 22-25].

In this study, we aimed to determine the biological function of AR in ccRCC VM. Mechanism dissection revealed that the lncRNA-TANAR, which is regulated by $\mathrm{AR}$, might increase the oncogene TWIST1 expression through competitive binding to TWIST1 mRNA to reduce the activity of Up-frameshift protein 1 (UPF1), the core factor required for nonsense-mediated mRNA decay [26].

\section{Results}

\section{AR expression may influence VM presence in ccRCC patients}

To clarify the clinical significance of VM on ccRCC, we collected 51 ccRCC human specimens along with their clinicopathological data and performed the HE \& PAS/ CD31 double staining to detect VM (Fig. 1a). The VM was significantly higher in Stage II and Stage III compared with Stage I (Fig. 1b). There is no statistical difference between males and females in any TNM Stage (Supplementary Fig. 1a). However, the result shows the $\mathrm{VM}$ occurs more frequently in males than in females when both had a high degree of malignancy (Stage II and Stage III) (Fig. 1c). Interestingly, based on Higgins renal microarray dataset [27] and the cancer genome atlas (TCGA) DNA copy number data, we found both AR mRNA and genomic DNA content increased in ccRCC (Fig. 1d, e). Next, we detected the AR expression via IHC in 51 ccRCC samples ( 36 males and 15 females), then separated patients into the AR-positive group and the AR-negative group (Fig. 1f). As shown in Fig. 1g, AR expression is positively correlated with higher VM formation. Moreover, immunofluorescence (IF) analysis in human clinical samples revealed that high AR expression was positively correlated and colocalized with Laminin $5 \gamma 2$, a specific VM marker [28] (Fig. 1h).

To further validate the positive correlation between $\mathrm{AR}$ and VM formation in vitro, we treated RCC $786 \mathrm{O}$ AR-low-positive cell line and SW839 AR-high-positive cell line with $10 \mathrm{nM}$ dihydrotestosterone (DHT) and $10 \mu \mathrm{M}$ enzalutamide (Enz), an FDA approved antiandrogen, respectively. As shown in Fig. 1i, $1 \mathrm{j}$ and Supplementary Fig. 1c, AR agonist DHT could increase both Matrigel-coated 2D and collagen I-based 3D VM formation, while AR antagonist Enz dramatically suppressed 2D and 3D VM formation only in the ARpositive cell line. Next, we knocked down the AR expression via adding two AR-shRNA (shAR ${ }^{1 \#}$ and shAR ${ }^{2 \#}$ ) in RCC AR-positive SW839 cells (Fig. 1k, left panel and Supplementary Fig. 1g) and OSRC-2 cells Supplementary Fig. 1d, and found a decreased 2D and 3D VM formation (Fig. 11, 1m, left panel and Supplementary Fig. 1e-i). In contrast, overexpressing AR via adding AR-cDNA (oeAR) in AR-weakly positive 7860 cells (Fig. 1k, right panel) and SW839 cells (Supplementary Fig. 1c) led to more VM formation in both $2 \mathrm{D}$ and $3 \mathrm{D}$ conditions (Fig. 11, $1 \mathrm{~m}$, right panel).

Taken together, results from Fig. 1a-m and Supplementary Fig. 1a-i demonstrate that AR may play a positive role to affect the ccRCC VM formation. 

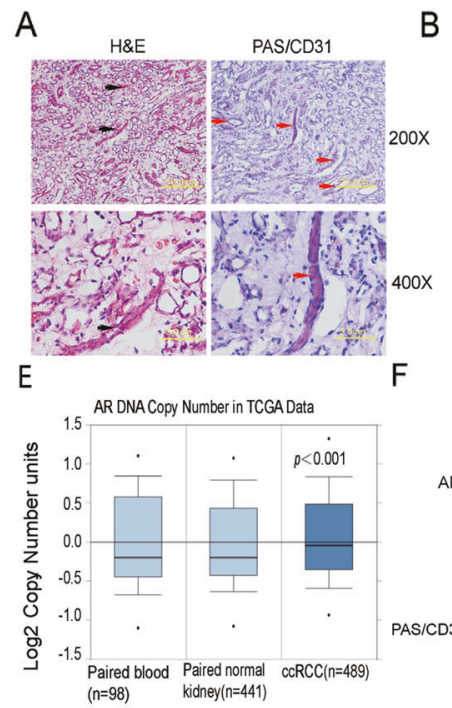

F
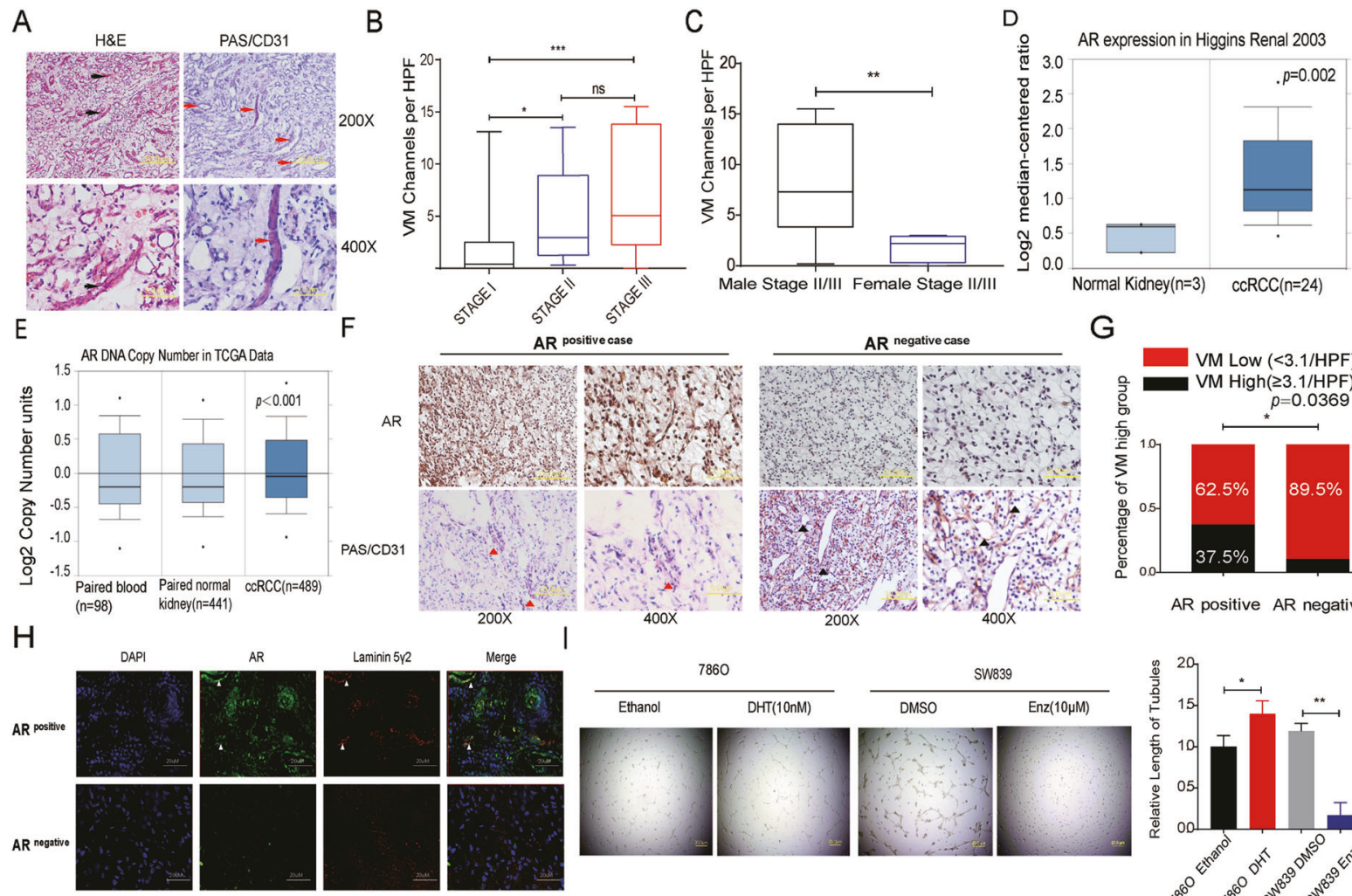

$J$
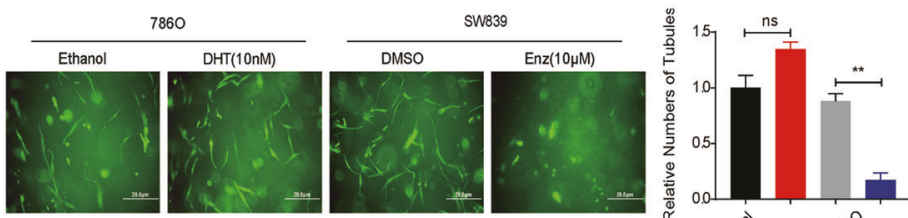

L
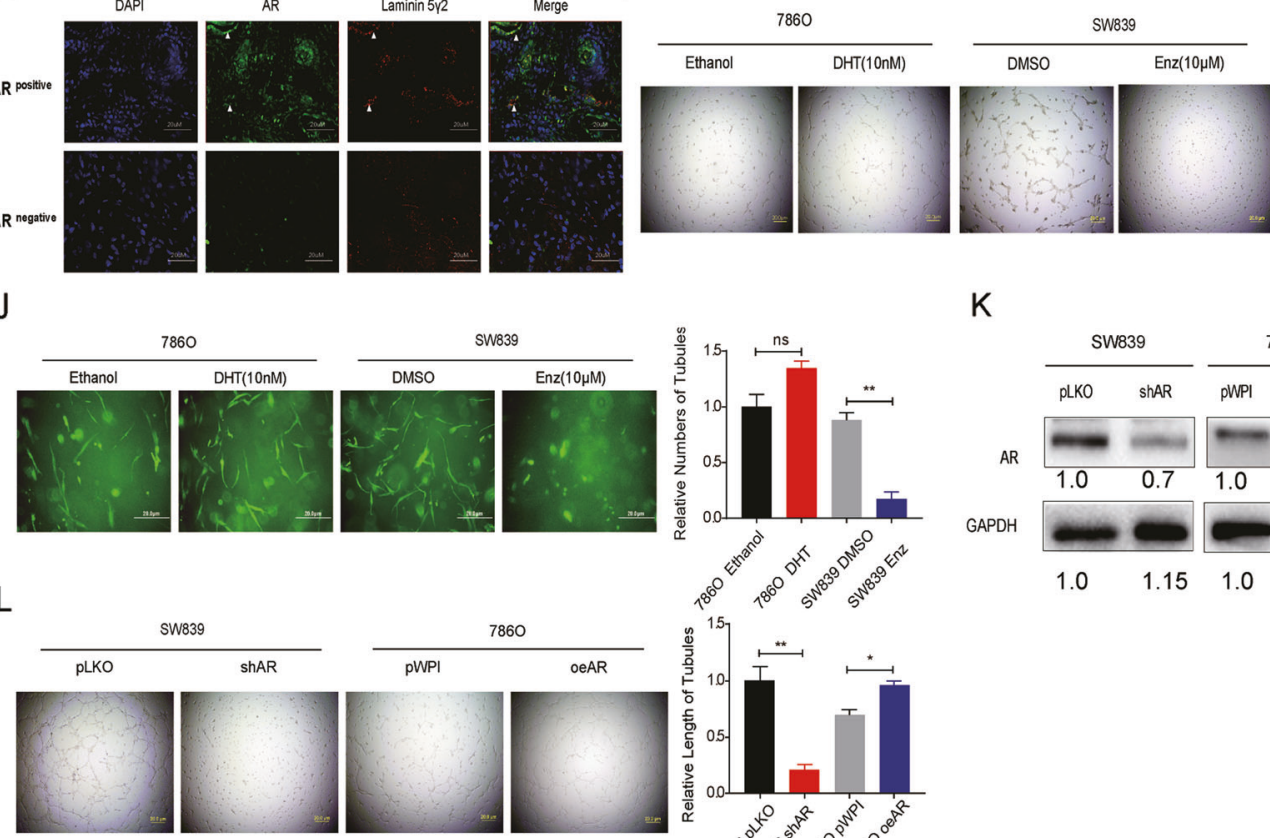

G

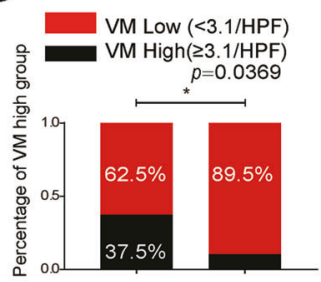

AR positive $A R$ negative

K
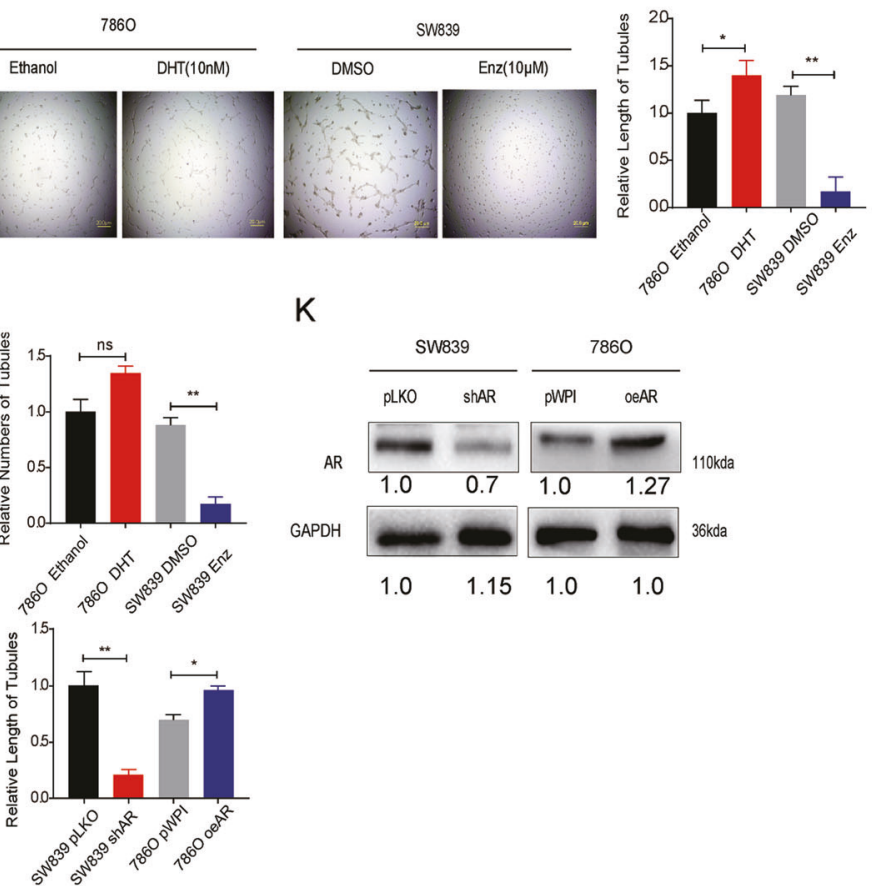

M
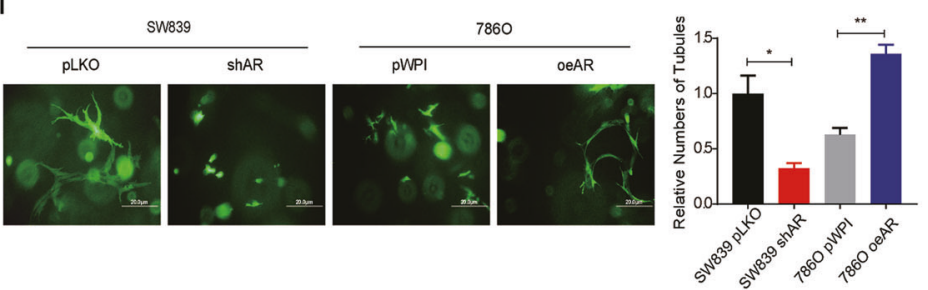

\section{AR can induce TWIST1 to promote VM formation in CCRCC in vitro}

To dissect the molecular basis for AR's effect on ccRCC VM formation, we screened the known critical genes linked with VM via qRT-PCR assay in RCC $786 \mathrm{O}$ cells after adding ARcDNA (Fig. 2a, left panel) or RCC SW839 cells after adding
shAR plasmid (Fig. 2a, right panel) to examine if any of those VM-related genes may be responsive to altering AR expression $[29,30]$. The result showed that TWIST1 mRNA level was the only VM-related gene positively correlated with AR (threshold $\geq 0.3$ fold of Log10) (Fig. 2a). Consistent with this, western blot assay further showed that knocking down AR in SW839 cells could decrease TWIST1, a dominant VM-promoting gene 
Fig. 1 AR promotes VM formation in ccRCC. a CD31/PAS and HE staining were utilized to identify the VM formation. Red arrows indicate the VM channels surrounded by tumor cells with CD31 negative staining and black arrows show the VM channel with visible blood cells inside. b VM channels per high-quality frame (HPF) in both TNM Stage II and III are higher than in Stage I. c The association between gender and VM formation in ccRCC Stage II/III patients. d The AR mRNA expression increases in ccRCC compared with normal kidney in Higgins renal microarray dataset. e TCGA DNA copy number databases (TCGA, http://tcga-data.nci.nih.gov/tcga/) show higher AR DNA copy number in ccRCC than in paired normal tissue and blood. $\mathbf{f} \mathrm{VM}$ formation per HPF in AR-positive expression group $(n=32)$ and AR negative expression group $(n=19)$. Red triangles show PAS+/CD31 - VM channels and black triangles show PAS+/CD31+ endothelial cell-dependent vessels. g Our statistical analysis of the correlation between AR and VM. h IF analysis revealed that in AR-positive sample VM numbers were more than in AR negative sample, laminin 5 gamma2 chain-positive channels were regarded as VM formation. Nuclei were stained with DAPI. i Matrigelcoated 2D VM tube formation assay for ethanol/10 nM DHT and DMSO/10 $\mu \mathrm{M}$ Enz treated 7860 and SW839 cells, respectively. j 7860 cells treated with ethanol/10 nM DHT (left panels) and SW839 cells treated with $\mathrm{DMSO} / 10 \mu \mathrm{M}$ Enz (right panels) were grown in collagen I matrix for 7 days to detect 3D VM tube formation assay. k Western blot assay for scramble control (pLKO) and knocked down AR (shAR) in SW839 cells (left panels), vector control (pWPI), or overexpressed AR (oeAR) in 7860 cells (right panels). l, m Matrigelcoated 2D VM assay (l) and the collagen-based 3D VM assay (m) showed shAR in SW839 cells could suppress VM formation and oeAR in 7860 cells could increase VM formation. For (i), (j), (l), and $(\mathbf{m})$, quantitations are at the right, and data are expressed as mean \pm S.D. $* p<0.05, * * p<0.01$, and $* * * p<0.001$ compared to the controls.

[31, 32], and overexpressing AR in 7860 cells had the opposite effect (Fig. 2b).

In order to confirm whether AR induced VM formation through TWIST1, we applied rescue experiments adding TWIST-cDNA (oeTWIST1) into SW839 cells and TWIST1shRNA (shTWIST1) into 7860 cells (Fig. 2c, d). The results revealed that shTWIST1 in 7860 cells could partially reverse the elevated VM formation induced by AR overexpression. In contrast, oeTWIST1 in SW839 cells increased VM formation, especially after knocking down the endogenous AR (Fig. 2e, f). Similarly, Harmine [33, 34], which is a TWIST1 inhibitor through its degradation at the protein level (Fig. 2g), could dramatically block the effect of overexpressing AR on VM formation of RCC cells (Fig. 2h-i).

Together, results from Fig. $2 \mathrm{a}-\mathrm{i}$ indicate that AR may function through modulating TWIST1 expression to influence the Matrigel-coated 2D and collagen I-based 3D VM formation in vitro.

\section{Human clinical sample analysis for TWIST1 expression in the ccRCC versus para-tumor non- cancerous tissues}

To examine the role of TWIST1 in ccRCC clinical samples, we detected its expression by IHC in 23 pairs of samples derived from ccRCC tumors and adjacent normal tissues (Fig. 2j) and the results showed a higher expression of TWIST1 was detected in tumors than in paired adjacent normal tissues $(p<0.001 ; n=23)$ (Fig. $2 \mathrm{k})$, which was consistent with the results extracted from TCGA mRNA database (Fig. 2l). Furthermore, AR is positively correlated with TWIST1 based on 51 ccRCC IHC samples (Fig. 2m). Additionally, based on TCGA online database UALCAN (http://ualcan.path.uab.edu/), we found elevating TWIST1 levels (using $25 \%$ of samples with the highest TWIST1 expression) led to a significantly lower survival rate in ccRCC patients (Fig. 2n). In addition, as our cohort is shown in Supplementary Fig. 1b, VM occurred more frequently in the TWIST1 high expression group.

\section{Mechanism dissection of how AR alters TWIST1 expression: via modulating the InCRNA-TANAR expression}

Since AR could elevate TWIST1 expression at both protein and mRNA levels (see Fig. 2a, b), we then focused on whether AR increases TWIST1 expression via transcriptional regulation. Results from $\mathrm{qPCR}$ assay performed on 7860 and SW839 cells treated for $2 \mathrm{~h}$ with $10 \mathrm{nM}$ DHT and $10 \mu \mathrm{M}$ Enz, respectively, showed no difference in mRNA levels, indicating AR may not regulate TWIST1 transcriptionally (Supplementary Fig. 2a). Intriguingly, after treating 7860 oeAR cells or SW839 shAR cells with actinomycin $\mathrm{D}$ for different periods of time to measure the decay of TWIST1 mRNA (Fig. 3a, b), we found that oeAR resulted in an increase in the half-life of TWIST1 mRNA, whereas shAR decreased its half-life implying that AR could stabilize TWIST1 mRNA. To further dissect the detailed mechanism, we tested whether AR could regulate miRNA targeting TWIST1 to exert its function (Fig. 3a, b). As miRNA usually destabilizes its target genes in the Ago2containing RISC complex (RNA-induced silencing complex) $[35,36]$, we performed immunoprecipitation of Ago2 followed by detection of TWIST1 mRNA. The results showed that overexpressing AR contributed to a slight increase of TWIST1 mRNA level in the Ago2 complex, indicating that AR may not modulate TWIST1 via altering miRNAs (Supplementary Fig. 2b).

We then moved to the lncRNAs, as recent studies indicated that IncRNA may bind to the 5'UTR of target mRNA to regulate mRNA level [37, 38]. To examine whether lncRNAs might be involved in regulating TWIST1 mRNA level, we first applied a bioinformatic analysis to identify potential lncRNAs capable of interacting with TWIST1 mRNA 5'UTR and overlapped the results with $\operatorname{lncRNAs}$ overexpressed $(\log \mathrm{FC}>1, P<$ 0.05) in Sunitinib resistance cells from the GSE69535 dataset (Fig. 3c and Supplemental Table 1). As shown 

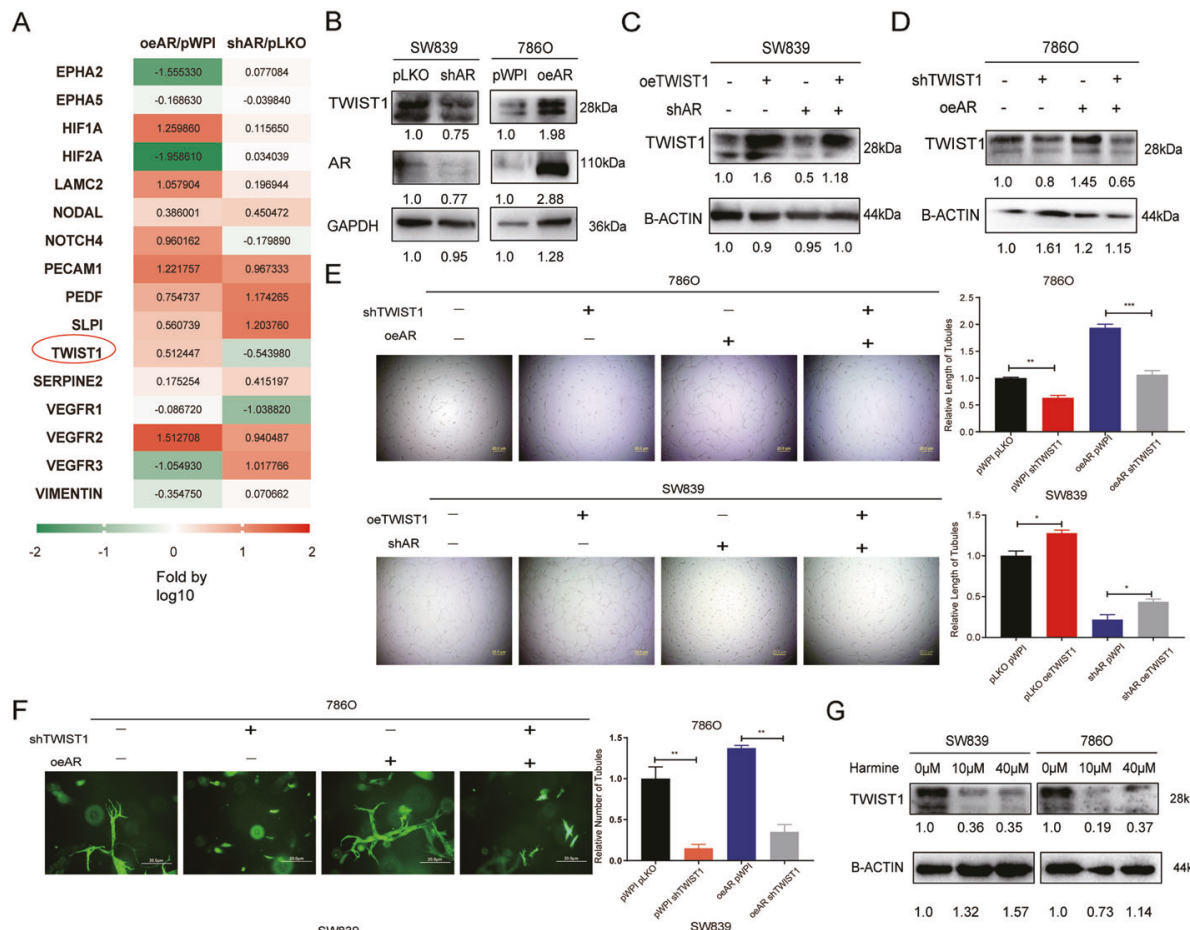

G
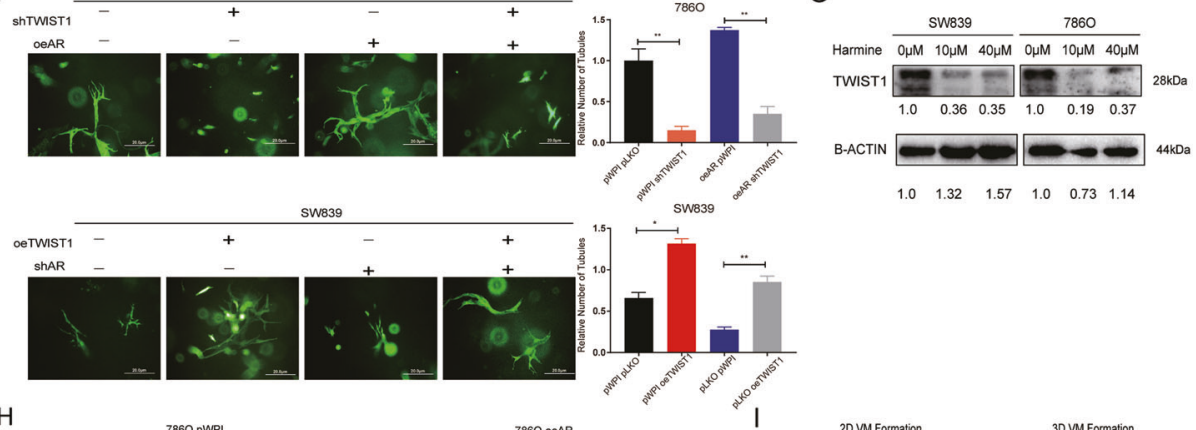

$\begin{array}{llllll}1.0 & 1.32 & 1.57 & 1.0 & 0.73 & 1.14\end{array}$
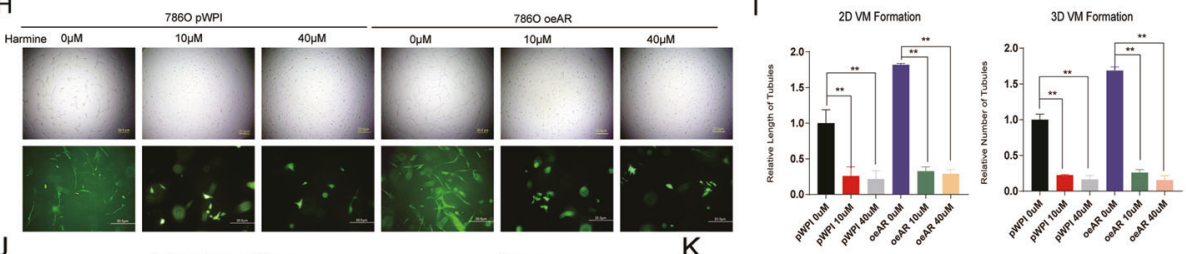

J

Adjacent normal tissue Tumor

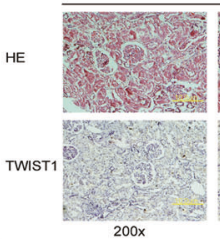

L

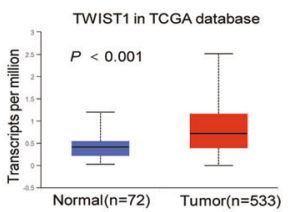

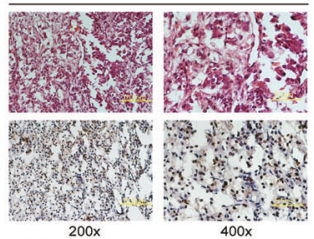

M

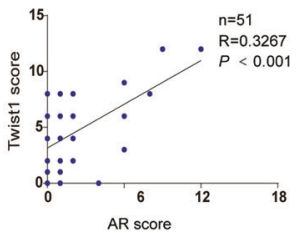

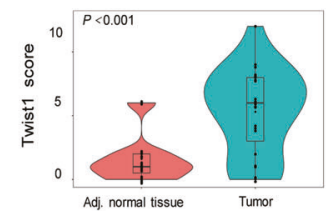

$\mathrm{N}$

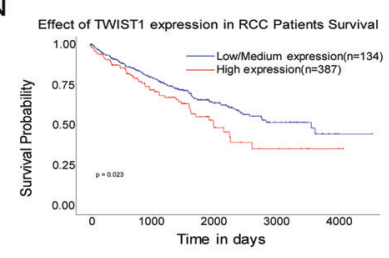

in Fig. 3d, five candidates (ENST00000436510.1, ENST00000471626.1, ENST00000593604.1， ENST00 000425110.1, and ENST00000377977.3) changed significantly after altering AR in 7860 and SW839 cells. Furthermore, results from the RNA pull-down assay via TWIST1 mRNA showed that overexpressing AR in
7860 cells could lead to ENST00000425110.1 and ENST00000377977.3 binding more to TWIST1 mRNA compared with pWPI group (Fig. 3e).

At the same time, knocking down these candidates (Supplementary Fig. 2c) indicated that knockdown of ENST00000425110.1 and ENST00000377977.3 could 
Fig. 2 AR enhances ccRCC VM formation via altering TWIST1 expression. a The qRT-PCR assays for the 16 genes related to VM formation in 7860 cells (left) transfected with AR-cDNA (oeAR) versus control (pWPI) and SW839 cells (right) transfected with shRNA-AR (shAR) versus mock (pLKO). b Western blot assay for AR and TWIST1 protein levels in SW839 cells (left) with pLKO or shAR and in 7860 cells (right) with pWPI or oeAR. c-d Western blot assays were performed on SW839 cells (c) transfected as indicated as well as 7860 cells transfected as indicated (d). e 2D Matrigel-coated VM assays were performed in 7860 cells transfected as indicated (upper panels) and SW839 cells transfected as indicated (lower panels). f 3D collagen I-based VM assays were performed in 7860 cells transfected as indicated (upper panels) and SW839 cells transfected as indicated (lower panels). g Western blot assays to detect TWIST1 protein levels in SW839 (left) and 7860 (right) cells after treating with $10 \mu \mathrm{M}$ or $40 \mu \mathrm{M}$ Harmine for $48 \mathrm{~h}$. h-i 2D Matrigelcoated (upper panels) and 3D collagen I-based (lower panels) VM assays were performed after treating 7860 cells transfected with pWPI or oeAR with TWIST1 inhibitor, Harmine. $\mathbf{j}$ Representative H\&E and IHC staining of TWIST1 in adjacent noncancerous tissues (left) compared to paired ccRCC tissues (right). $\mathbf{k}$ The IHC score of TWIST1 between 23 paired adjacent tissue and ccRCC tumors. $\mathbf{I}$ The mRNA level of TWIST in ccRCC samples $(n=534)$ and adjacent normal tissues $(n=72)$ from TCGA database. $\mathbf{m}$ The correlation between AR and TWIST1 level based on IHC score $(n=51)$. n Overall survival probability of ccRCC patients was negatively correlated with TWIST1 mRNA expression based on TCGA database. For (e) and (f), quantitations are at the right, and data are expressed as mean \pm S.D. $* p<0.05$ and $* * p<0.01$ compared to controls.

suppress TWIST1 expression more in the oeAR group than in the control group (Fig. 3f). In addition, western blot assays revealed that only ENST00000425110.1 overexpression could rescue the decline in TWIST1 protein induced by knocking down AR. As expected, the overexpressed AR-elevated TWIST 1 protein level decreased drastically via knockdown of ENST00000425110.1 (TANAR) (Fig. 3g, h and Supplementary Fig. 2d-f). Consistent with these results, we also found that overexpressing ENST00000425110.1 in SW839 cells could increase VM formation, especially after knocking down the endogenous AR (Fig. 3k). In contrast, overexpressed AR-increased ccRCC VM could be partially blocked by adding ENST00000425110.1-shRNA in 7860 cells (Fig. 3i-1). Consistent with this, activating AR through $10 \mathrm{nM}$ DHT in 7860 cells could increase ENST00000425110.1 expression while blocking AR with $10 \mu \mathrm{M}$ Enz in SW839 cells led to a decrease in its expression (Supplementary Fig. 2g, h). Therefore, we named this lncRNA as TANAR (Twist1 Associated Long Noncoding RNA regulated by AR) based on the above analyzes and focused on this lncRNA for the remaining studies.

Through Ensemble software and Lncpedia database, we found that the position of TANAR, with little proteincoding function, is in chromosome 2: 240,981,515240,986,072 (Supplementary Fig. 3a, b). Furthermore, subcellular fraction analysis, as well as FISH assay, revealed that TANAR was distributed in both cytoplasm and nuclei of cells (Fig. 3m, n), consistent with online analysis (http://www.csbio.sjtu.edu.cn/bioinf/lncLocator/) predicting the location of TANAR (Supplementary Fig. 3c).

Together, from Fig. 3a-n, Supplementary Fig. 2a-f, and Supplementary Fig. 3a-c, we found a novel lncRNATANAR that is regulated by $A R$ via altering TWIST1 expression and inducing VM formation in ccRCC cells.

\section{Mechanism dissection of how AR alters TANAR expression: via transcriptional regulation}

To further dissect the potential molecular mechanism of how AR regulates the TANAR expression at the transcriptional level, we applied the Ensembl and PROMO 3.0 websites to search for the androgen response elements (AREs) in the $2 \mathrm{~kb}$ region of the TANAR promoter by using the JASPAR database (Fig. 4a) and detected five putative AREs (I -1150nt to $-1136 \mathrm{nt}, \mathrm{II} / \mathrm{III}-602 \mathrm{nt}$ to $-586 \mathrm{nt}$ and VI/V -94nt to $-41 \mathrm{nt}$ ) (Fig. 4b). Next, we performed the chromatin immunoprecipitation (ChIP) assay, and results revealed that AR could specifically bind to ARE II\&III, but not the other AREs (Fig. 4c). Furthermore, we mutated the critical sequences of ARE II/III and inserted the mutant (MT) promoter region of TANAR into pGL3 luciferase plasmid as well as the wild-type (WT) promoter (Fig. 4d). As expected, the luciferase assay results showed that knocking down AR or adding Enz $10 \mu \mathrm{M}$ significantly lessened luciferase activity in SW839 cells transfected with WT reporter, but not in the cells with the MT reporter (Fig. 4e left and Supplementary Fig. 3e). In contrast, overexpressing AR or adding DHT $10 \mathrm{nM}$ could drastically increase luciferase activity in 7860 or SW839 cells with the WT reporter, but not in the cells with the reporter containing the MT ARE (Fig. 4e right and Supplementary Fig. 3d).

Together, results from Fig. $4 \mathrm{a}-\mathrm{e}$ and Supplementary Fig. 3d-e suggested that AR could directly increase TANAR expression transcriptionally through binding to the ARE II/III.

\section{Mechanism dissection of how TANAR can alter TWIST1 expression: via modulating nonsense- mediated mRNA decay by competitive binding of UPF1 to TWIST1 mRNA}

To dissect the molecular mechanism underlying AR/ TANAR's regulation on TWIST1 expression, especially the impact of AR on TWIST1 mRNA stability (see Fig. 3a, b), we hypothesized that TANAR could modulate TWIST1 mRNA stability via the TANAR-TWIST1 interaction, as was shown with the presence of TANAR in TWIST1 pulldown assay (see Fig. 3e) [37, 39, 40]. Indeed, mRNA stability assay, using treatment with actinomycin, revealed that knocking down TANAR could block the overexpressing 


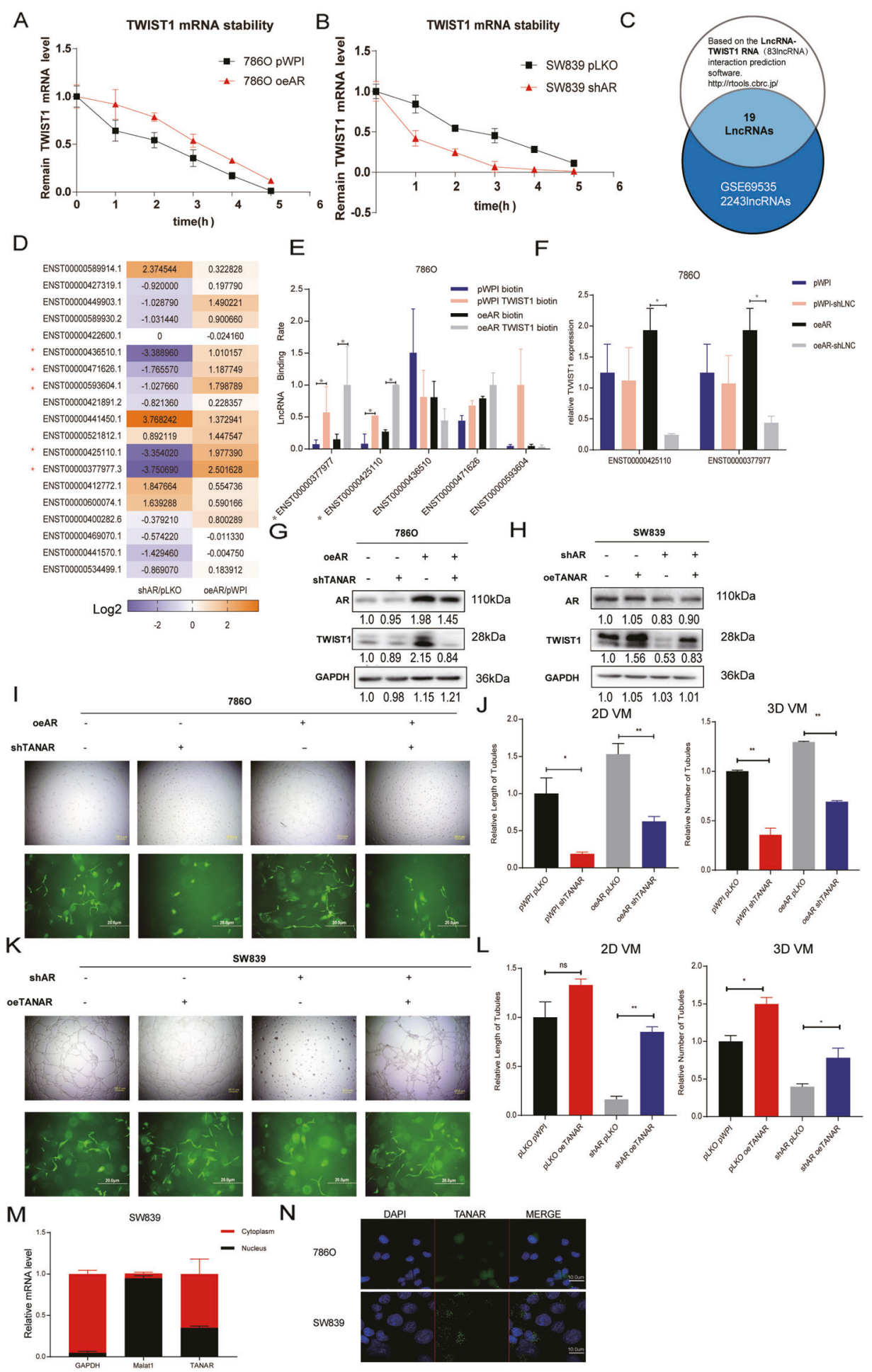

AR-increased TWIST1 mRNA stability (Fig. 5a). Furthermore, to test whether this binding is crucial for TANAR's regulation on TWIST1 mRNA, we constructed WT TANAR cDNA sequence and mutated it by deleting the TANAR-TWIST presumptive binding region (Fig. 5b and Supplementary Fig. 4a, b). Compared to the pWPI group,
7860 cells transfected with MT TANAR-cDNA failed to increase TWIST1 mRNA and protein levels (Fig. 5c, d). Moreover, mRNA stability assay, using actinomycin treatment, showed that AR knockdown-decreased TWIST1 mRNA stability could be rescued only by adding wild-type TANAR (Fig. 5e). The FISH assay in SW839 cells also 
Fig. 3 Mechanism dissection of how AR can increase TWIST1 expression: via IncRNA-TANAR. a, b 7860 cells were transfected with vector control (pWPI) or AR-cDNA (oeAR) (a) and SW839 cells were infected with mock control (pLKO) or AR shRNA (shAR) (b). After $48 \mathrm{~h}$, cells were incubated with $2 \mu \mathrm{g} / \mathrm{mL}$ actinomycin D for 0,1 , 2, 3, 4, and $5 \mathrm{~h}$. Total RNA was then analyzed by qRT-PCR to examine TWIST1 mRNA stability. c Bioinformatics analysis of potential lncRNAs that are associated with RCC resistance to Sunitinib in GSE69535 dataset and with predicted binding site to the mRNA of TWIST1 based on the RNA-RNA interaction prediction software, http://rtools.cbrc.jp/. d Real-time PCR of 19 potential candidate lncRNAs in SW839 cells infected with knocked down AR (shAR) compared with vector control (pLKO) and with adding AR-cDNA (oeAR) compared with scramble control (pWPI). e RNA pull-down assay via TWIST1 mRNA biotin identifies candidate lncRNAs ENST00000425110.1 and ENST00000377977.3, which can bind to TWIST1 mRNA more in 7860 oeAR cells compared with 7860 pWPI cells. f The qRT-PCR assay showed sh-ENST00000425110.1 and shENST00000377977.3 could partly block oeAR increased TWIST1 mRNA level in 7860 cells. g, i, j Knocking down TANAR reverses oeAR effect on TWIST1 protein level (g) and 2D (i, upper) and 3D (i, lower) formation in 7860 cells. Quantitation of (i) in (j). h-l Overexpressing TANAR could partly reverse the knockdown AR effect on TWIST1 protein level (h) and 2D (k, upper) and 3D (k, lower) formation. Quantitation of (k) in (l). m Real time-PCR for TANAR, Malat1, and GAPDH from RNA extracted from nuclear and cytoplasmic fractions. n RNA fluorescence in situ hybridization (FISH) demonstrated that TANAR was localized in both cytoplasm and nucleus of 7860 and SW839 cells. Data are expressed as mean \pm S.D. ${ }^{*} p<0.05, * * p<0.01$, and $\mathrm{ns}=$ not significant, compared to the controls.

showed that TANAR could colocalize with TWIST1 mRNA (left panel), and we found that using Image $\mathbf{J}$ colocalization analyzer the Pearson's correlation coefficient (PCC) is 0.6554 (right panel) (Fig. 5f). Taken together, these data confirmed that the stabilizing effect of TANAR relies on its direct binding of TWIST1 mRNA.

Intriguingly, based on Ensembl database (http://uswest. ensembl.org/) and individual-nucleotide-resolution UV cross-linking and immunoprecipitation (iCLIP) performed by Zünd [41], TWIST1 mRNA could interact with the indispensable component for nonsense-mediated mRNA decay (NMD)-UPF1 through at least 12 binding sites (Supplementary Table 2), and then be regulated by NMD process via rapid degradation as its mRNA conforms to a canonical NMD structure (Supplementary Fig. 4c) [26].

To test whether TANAR could alter TWIST1 mRNA via influencing NMD, we performed a western blot to see the effect of TANAR on NMD core factors, UPF1, and SMG1 [42] expression. We found that overexpressing TANAR could not reduce either UPF1 or SMG1 protein levels (Supplementary Fig. 4d). However, the RNA immunoprecipitation assay by pull-down of TWIST1 mRNA using biotin-conjugated antisense oligonucleotide revealed that ectopic expression of wild-type TANAR could effectively diminish TWIST1 mRNA-UPF1 interaction in ccRCC, while their interaction was increased after knocking down
TANAR (Fig. 6a-d). Consistent with that, overexpressing wild-type TANAR, but not mutant TANAR, reduced TWIST1 level in the UPF1 immunoprecipitation (Fig. 6e). Knocking down TANAR significantly increases the TWIST1 level in UPF1 immunoprecipitation (Fig. 6f).

In order to further validate the function of TANAR on the NMD process of TWIST1, we generated luciferase report constructs replacing TWIST1 coding region with luciferase cDNA while maintaining the overall gene structure of TWIST1 genomic locus (pWPI-luc-TWIST1). We also generated two mutant reporters with mutations in the conserved splicing sequence to eliminate the NMD initiation (pWPI-luc-mutant 1 ) and TANAR-interacting region in the $5^{\prime}$ UTR (pWPI-luc-mutant 2) (Fig. 6g). As expected, the results showed that overexpressing AR could significantly increase luciferase activity in 7860 cells with pWPI-lucTWIST1, but not in the cells with either pWPI-luc-mutant 1 or pWPI-luc-mutant 2 (Fig. 6h). Consistent with this, knocking down AR significantly reduced luciferase activity in SW839 cells transfected with pWPI-luc-TWIST1, but not in the cells with either of the 2 mutant plasmids (Fig. 6i). When treating cells with DHT or Enz, we found the same tendency (Supplementary Fig. 4e, f). Moreover, only 7860 cells cotransfected with WT TANAR cDNA sequence and pWPI-luc-twist1, not with TANAR MT TANAR-cDNA or pWPI and pWPI-luc-mutant 1 or pWPI-luc-mutant 2, showed increased luciferase activity (Fig. 6j). The luciferase activity decreased only when knocking down TANAR in SW839 cells transfected with pWPI-luc-TWIST1 (Fig. 6k).

Together, results from Fig. 6a-k and Supplementary Fig. 4a-f suggest TANAR suppresses UPF1-TWIST1 mRNA interaction, thus reduces nonsense-mediated decay of TWIST1 mRNA to increase its mRNA stability (diagram in Fig. 61).

\section{Preclinical study using in vivo mouse model to confirm the role of AR/TANAR/TWIST1 axis in CCRCC VM}

To further test the validity of the above in vitro data, we applied the orthotopic ccRCC xenograft mouse model. We generated stable clones of 7860 cells with luciferase expression with overexpressed AR and/or sh-TANAR as well as a control, with 5 mice/group (1: Scr + luc; 2: oeAR + luc; 3: sh-TANAR + luc; and 4: oeAR + sh-TANAR + luc). A total of $1 \times 10^{6} 7860$ cells mixed with matrigel were inoculated into the left kidney capsule of nude mice and tumor progressions were evaluated via the non-invasive in vivo imaging system (IVIS). After 6 weeks, we observed that increased bioluminescence signals in the whole mice (Fig. 7a-d), as well as in the left kidney in the oeAR xenografted groups while knocking down TANAR could partly reverse the oeAR-increased high chemiluminescence 
A

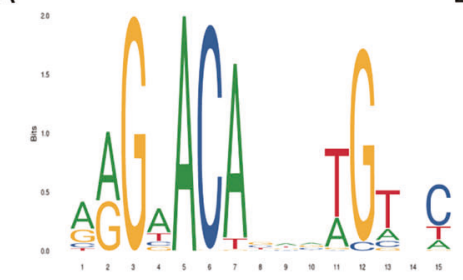

D

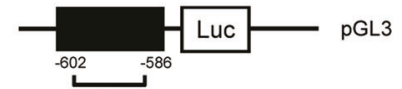

Wild-type:......AAAAACAGAGAGTCCC...... Mutant : .......AAGGATCCGGATCCCC.....
B

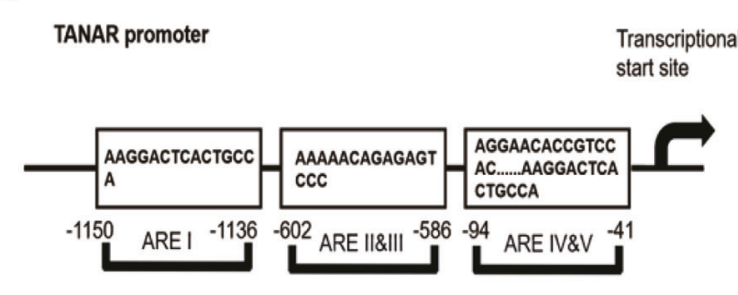

C

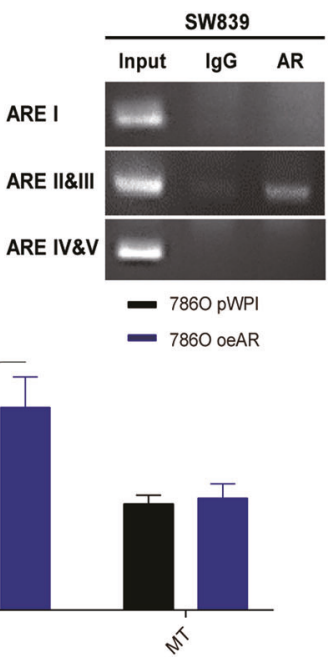

Fig. 4 Mechanism dissection how AR regulates TANAR expression: via transcriptional regulation. a ARE motif sequence identified with JASPAR. b The structure of ARE binding site in $2 \mathrm{~kb}$ TANAR promoter region. $\mathbf{c}$ ChIP assay confirmed AR could directly bind with TANAR AREII/III ( -602 nt to $-586 n t)$. d Schematic diagram of wildtype and mutant pGL3-TANAR promoter-reporter constructs. e, f Co- transfection of ARE wild-type (WT) or mutant (MT) TANAR promoter pGL3-Luciferase plasmids into SW839 cells with pLKO or shAR (e) and 7860 cells with pWPI or oeAR (f). The luciferase reporter assay was performed to detect promoter activity. The data are means \pm S.D. $* p<0.05$, and $n s=$ not significant, compared with control.

survival in patients with ccRCC [43, 44]. Similarly, based on 51 ccRCC clinical samples, we found a higher tumor stage tends to possess more VM channels (Fig. 1b). Interestingly, across our cohort, VM formation exists predominantly in males compared to females in Stage II\&III (Fig. 1c). However, consistent with a previous study [44], once we brought in Stage I clinical data, VM formation shows no significant difference between male and female (Supplementary Fig. 1a), which could be partly due to the scarce incidence of VM in Stage I patients in a larger male patient population lowering overall VM and a lack of gender difference (Fig. 1b).

Mounting evidence has demonstrated that AR functions as an oncogene in ccRCC, promoting progression and hematogenous metastasis $[5,6,22]$, despite the presence of few retrospective literature-based on the TCGA database implied AR may contribute to better prognosis in RCC [9]. However, its role in VM formation remains unclear. Based on our formalin-fixed, paraffin-embedded (FFPE) ccRCC tissue samples, expression of AR was detected more frequently in patients with higher VM presence, indicating that AR was positively correlated with VM formation $(R=$ 0.3947; $P<0.001$; Fig. 1 d, e). Although AR could act as a marker for the aggressive VM, the clinical data revealed that some AR negative and VM positive cases do exist, suggesting that AR may not be the exclusive regulator of VM. Consistent with pathological data, ectopic expression or DHT-induced activation of AR increases, whereas knockdown of AR or Enz-induced inactivation of AR decreases, the classical Matrigel-coated 2D VM formation. In 2017, Velez developed a de novo 3D in vitro collagen-induced 
A

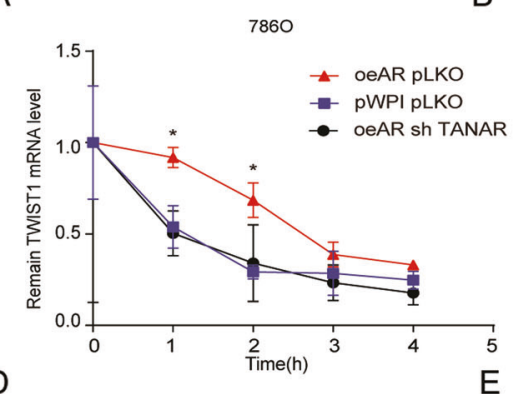

B E
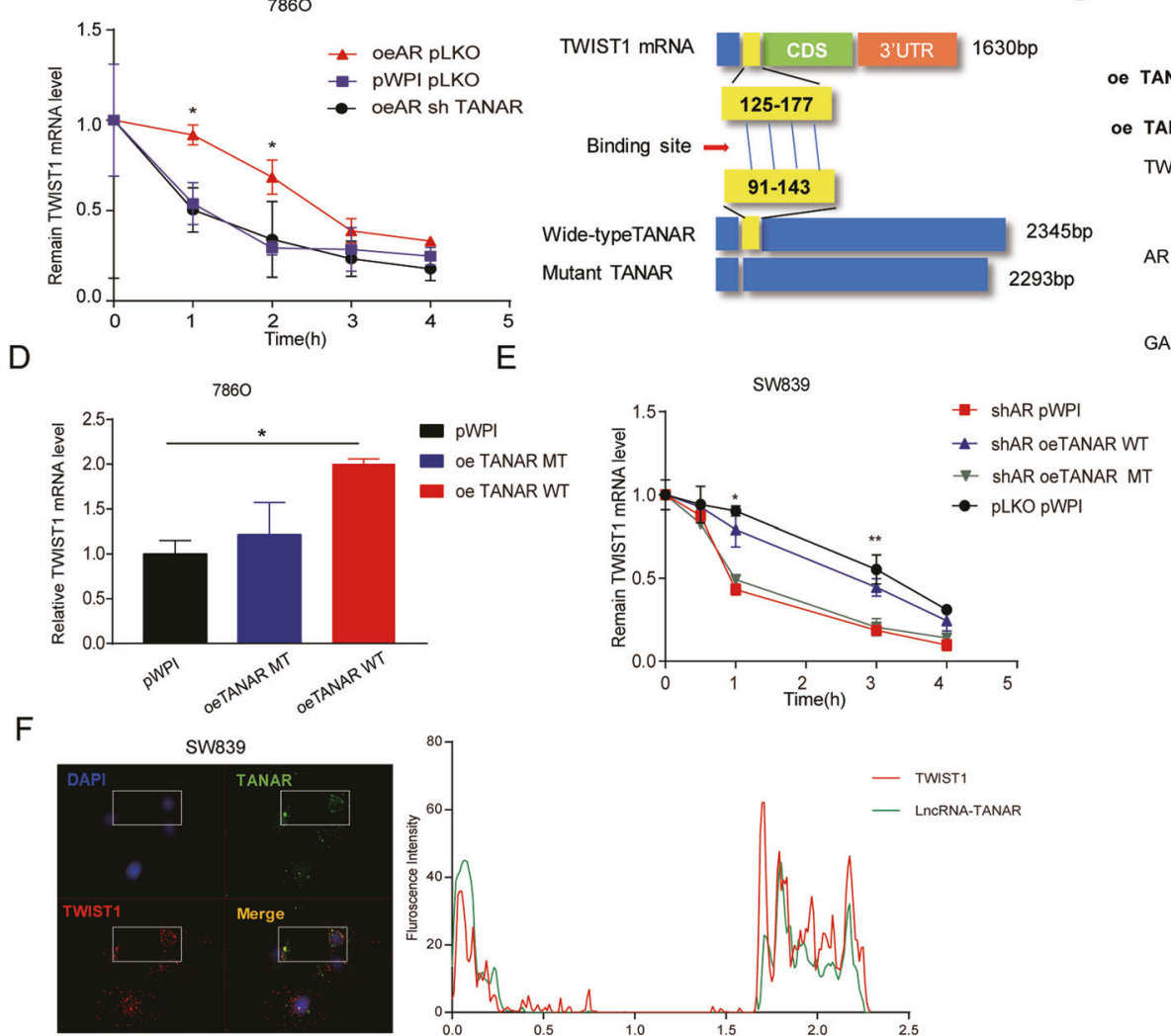

C

oe TANAR MT

- oe TANAR WT

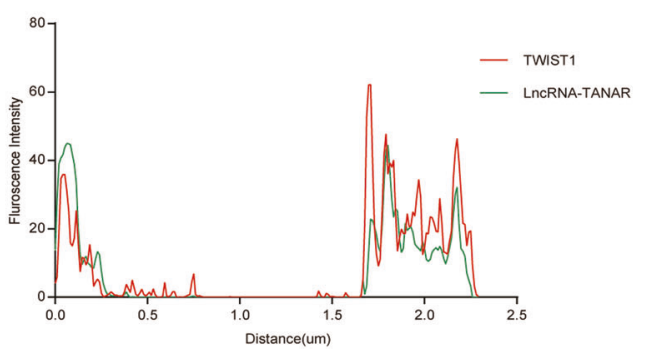

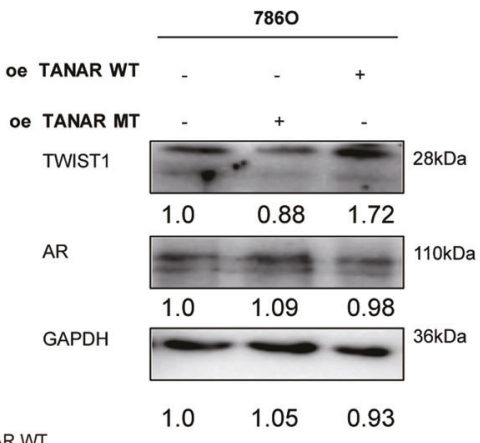

Fig. 5 Mechanism dissection how TANAR modulates TWIST1 expression: via stabilizing TWIST1 mRNA. a 7860 cells transfected with oeAR pLKO, pWPI pLKO, or oeAR shTANAR were treated with $2 \mu \mathrm{g} / \mathrm{ml}$ actinomycin D for designed times. Real-time RT-PCR was performed to examine the mRNA stability of TWIST1. b Sketch map showed the construct of wild-type TANAR and mutant TANAR. c Western blot assay showed the influence of ectopic wild-type (WT) and mutant (MT) TANAR on TWIST1 protein levels in $786 \mathrm{O}$ cells. d RT-PCR showed the influence of ectopic WT and Mut TANAR on TWIST1 mRNA level in 7860 cells. e SW839 cells expressing shAR

pWPI, shAR oeTANAR WT, shAR oeTANAR MT, or pLKO pWPI, were treated with $2 \mu \mathrm{g} / \mathrm{ml}$ actinomycin $\mathrm{D}$ for the designed periods of time. Real-time RT-PCR was performed to examine the mRNA stability of TWIST1. f Co-localization of TANAR (green, upper right) and TWIST1 mRNA (red, lower left) signals using RNA FISH. Nuclei were stained with DAPI (upper left lane). The lower right frame indicates the co-localized region as calculated by Image $J$ colocalization analyzer software. The data are presented as means \pm S.D. ${ }^{*} p<$ $0.05, * * p<0.01$, and $\mathrm{ns}=$ not significant, compared with control.

migration procedure to detect VM. We utilized this 3D collagen-I-induced model to further confirm AR's influence on VM formation. Moreover, we have also proved the role of $\mathrm{AR}$ in the formation of $\mathrm{VM}$ in vivo via the orthotopic implantation model, finding increased VM formation, increased tumor progression, and more metastases in xenografts established by cells with AR overexpression. Taken together, our study highlights the significance of AR in both in vitro and in vivo VM formation in a physiological way for the first time.

A previous study revealed that AR could upregulate TWIST1 via ETV1 in prostate cancer [45]. Similarly in RCC cells, AR can also increase TWIST1 expression through an indirect mechanism through IncRNA-TANAR to impact RCC VM development. There appears a tissue-specific mechanism for AR to regulate TWIST1 expression. TWIST1 is a basic helix-loop-helix transcriptional factor, which plays important

role in epithelial-mesenchymal transition and VM in diverse types of tumors [33, 46, 47]. The previous literature-based on 163 ccRCC clinical samples revealed that elevated levels of TWIST1, which is mainly localized in the cytoplasm of ccRCC cells (98.8\%), was closely associated with higher stage, vascular invasion, and poor prognosis in RCC [48]. In addition, it has been reported that TWIST1 could transcriptionally regulate VE-cadherin, a transmembrane protein responsible for cell-cell adhesion and VM formation, in multiple types of tumor cells $[49,50]$. Not surprisingly, our clinical tissue samples demonstrated that TWIST1 expression is positively correlated with VM formation (Supplementary Fig. $1 \mathrm{~b} ; R=0.34 ; P<0.001$ ), which is consistent with our in vivo or in vitro data. Furthermore, we treated ccRCC cell with Harmine, a naturally occurring beta-carboline alkaloid widely used herb, as a TWIST1 inhibitor selected through the unbiased screen and validated in the lung cells $[33,34]$, and found that it led to 
A

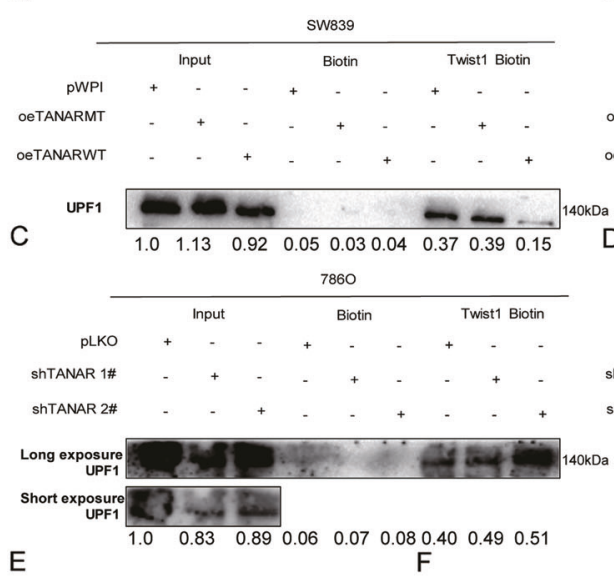

B
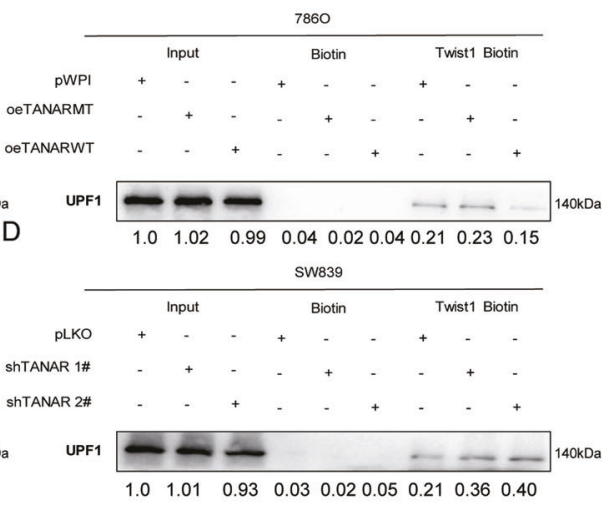

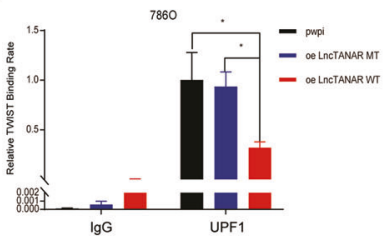

G
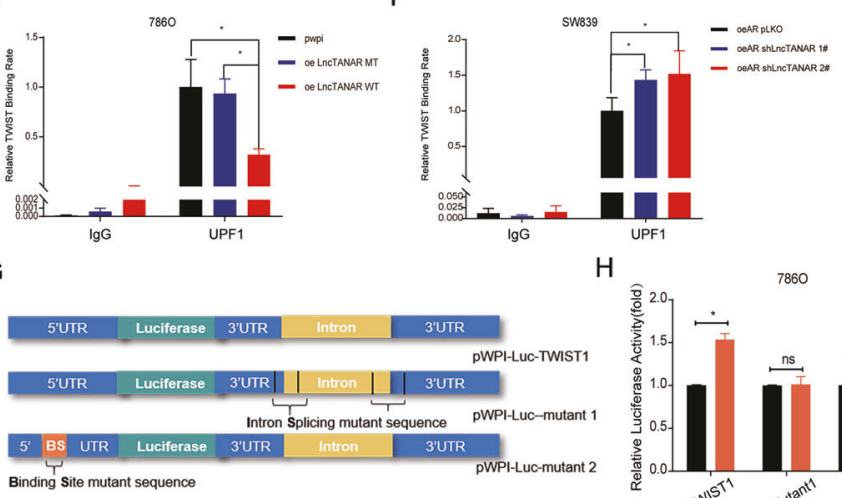

7860
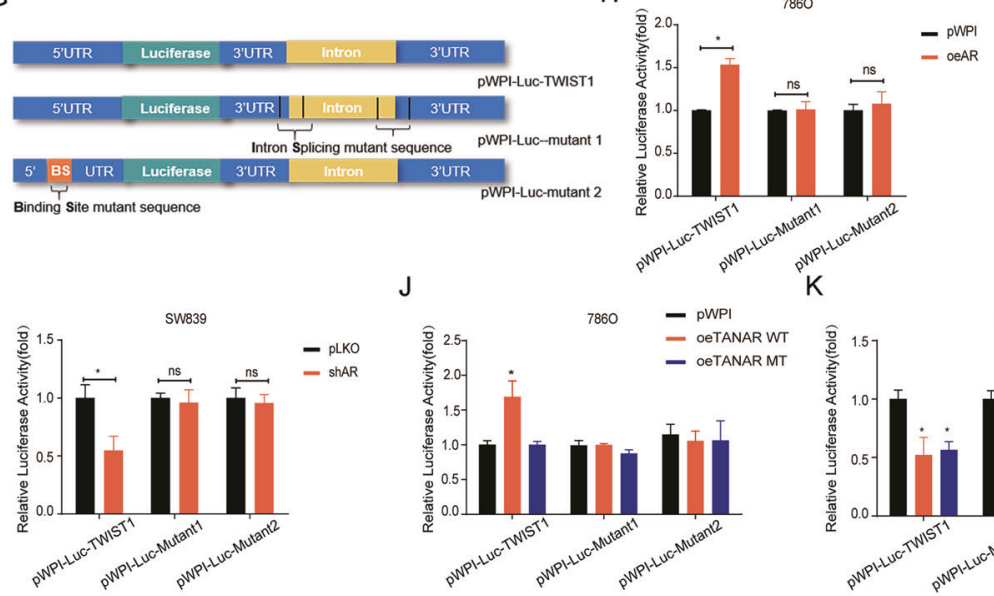

J

L
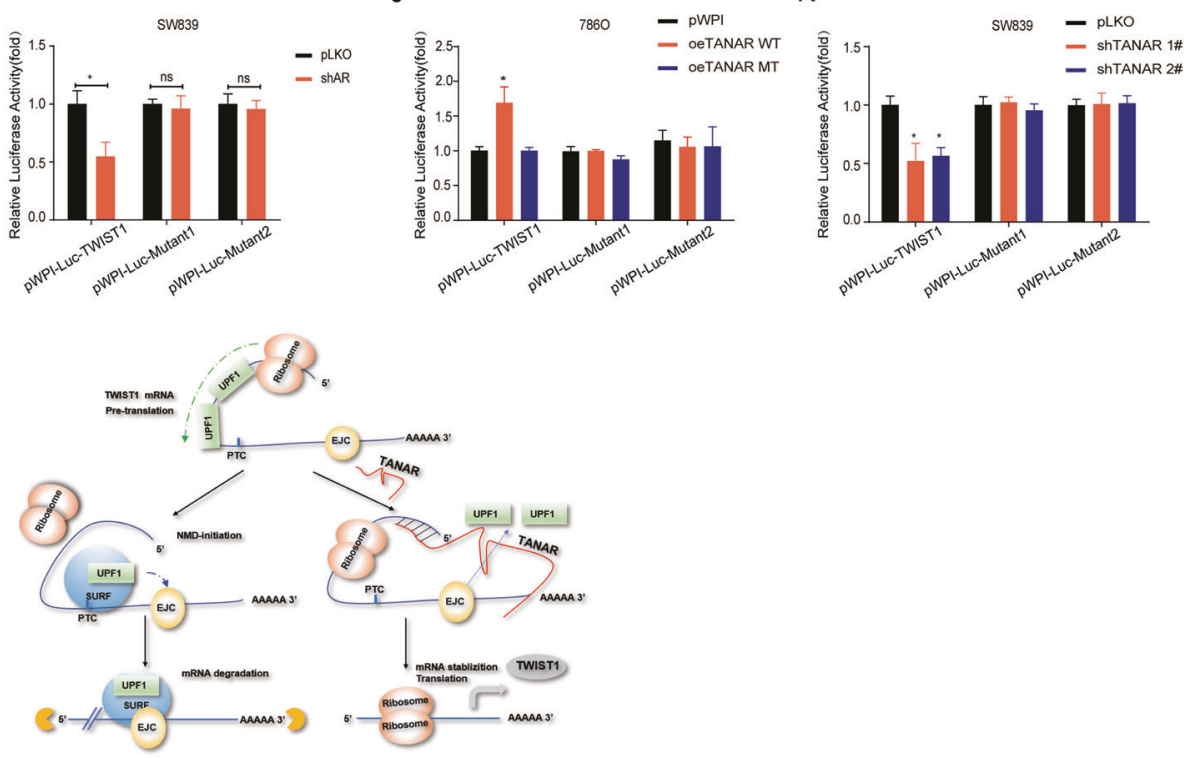

dramatic degradation of TWIST1 protein at either $10 \mu \mathrm{M}$ or $40 \mu \mathrm{M}$ while also drastically diminished VM formation in ccRCC cells. Thus, targeting TWIST1 signaling might be a promising therapy for ccRCC with high VM formation.

Increasing evidence indicates that TWIST1 could be posttranscriptionally modulated via noncoding RNA [51-53].
The lncRNAs could sponge microRNAs to regulate the TWIST1 expression, and then influence tumorigenesis. Moreover, NMD, which is a conserved cellular mRNA surveillance system, can degrade TWIST1 transcripts via recognition of termination codons before the last exon in TWIST1 mRNA [54, 55]. On the one hand, cancer cells 
Fig. 6 Mechanism dissection how TANAR modulates TWIST1 stability: via diminishing TWIST1 nonsense-mediated decay by interrupting the interaction between UPF1 protein and TWIST1 mRNA. a-d SW839 (a and d) or 7860 (b and c) cells were transfected with pWPI, oeTANAR MT, oe TANAR WT, shTANAR 1\#, or shTANAR 2\# as indicated. Cell lysates were incubated with in vitro biotin-labeled sense or antisense probes against TWIST1 mRNA for the RNA pull-down assay. Western blot assays were performed to test levels of UPF1 in sediments from the pull-down. $\mathbf{e}, \mathbf{f}$ Cell lysates of 7860 (e) cells expressing control pWPI, oe TANAR MT, or oe TANAR WT and SW839 (f) cells expressing oeAR control pLKO, oeAR shTANAR 1\#, or oeAR shTANAR 2\# were incubated with biotin-labeled sense or antisense probes against TWIST1 mRNA for RNA pull-down assay and RT-PCR analysis to test TWIST1 mRNA levels. g Sketch map showed the construct of pWPI-lucTWIST1 and pWPI-luc-mutant 1 (intron splicing mutant) and pWPIluc-mutant 2 (binding site mutant). h, i Co-transfection of 7860 cells with pWPI or oeAR (h) or SW839 cells (i) with pLKO or shAR and both cells types with pWPI-luc-TWIST1, pWPI-luc-mutant 1 or pWPIluc-mutant 2 plasmids. The luciferase reporter assay was performed to detect promoter activity. $\mathbf{j}, \mathbf{k}$ Co-transfection of pWPI-luc-TWIST1, pWPI-luc-mutant 1 or pWPI-luc-mutant 2 plasmids into SW839 cells with pLKO or shTANAR1\# \&2\# (k), and 786 cells with pWPI, oeTANAR WT or oeTANAR MT (j). The luciferase reporter assay was performed to detect promoter activity. I Schematic diagram: LncRNA-TANAR could directly bind to TWIST1 mRNA, diminishing its interaction with NMD core factor, UPF1, thus stabilize TWIST1 mRNA. EJC exon junction complex; PTC premature termination codon, SURF SMG1-UPF1-eRF1-eRF3 complex. The data are means \pm S.D. $* p<0.05, * * p<0.01$, and $\mathrm{ns}=$ not significant, compared with control.

have utilized NMD to decrease gene expression by deliberate reduction of vital tumor-suppressor mRNAs [56]. On the other hand, cancer cells could fine-tune NMD activity to adapt to harsh microenvironments [57]. Previous studies have shown several lncRNAs could regulate mRNA decay via interacting with up-frameshift protein 1 (UPF1) [58, 59]. In this study, we identified a novel IncRNA-TANAR, as an AR-transcriptionally-regulated lncRNA, is able to promote TWIST1 mRNA stability by suppressing NMD via competitive binding with UPF1 to the TWIST1 mRNA 5'UTR. Intriguingly, previous studies showed that UPF1 mostly targets $3^{\prime}$ untranslated region of mRNA to exert NMD function [60] while TANAR binds to the $5^{\prime} \mathrm{UTR}$ region of the TWIST1 mRNA. To further validate the role of NMD in regulating TWIST1 mRNA, we scrutinized iCLIP-seq data and found 12 confirmed UPF1 protein-TWIST1 mRNA binding sites [26], partly overlapping with the predicted TANAR-TWIST1 mRNA interaction region. Based on our RIP assays and luciferase analyzes (Fig. 6a-k), we show lncRNA-TANAR increases TWIST1 mRNA stability via directly binding to its $5^{\prime} \mathrm{UTR}$ with disruption of UPF1 initiating nonsense-mediate TWIST1 mRNA decay. This suggests a role of $5^{\prime}$ UTR in regulating NMD likely through the loop formation between the $5^{\prime} \mathrm{UTR}$ and $3^{\prime} \mathrm{UTR}$ of mRNA.

In conclusion, we characterized a new long noncoding RNA TANAR transcriptionally regulated by AR, which influences VM formation by decreasing TWIST1 mRNA nonsense-mediated decay. Targeting the AR/lncRNATANAR/TWIST1 axis could be a promising strategy for the development of better treatment of ccRCC.

\section{Methods and materials}

\section{Patients and samples}

A total of 51 histologically confirmed ccRCC tissue samples with 23 paired adjacent noncancerous tissues were collected between August 1, 2014 and February 1, 2016 from the Department of Urology, the Second Affiliated Hospital of Harbin Medical University (Harbin, China). Patients were excluded if they had been treated previously with neoadjuvant chemotherapy or TKIs. All samples collected for use in research after patients signed the consent of the scientific ethics were fixed in $10 \%$ formalin and then embedded in paraffin. Our research was approved by the Institutional Review Board of the hospital in advance.

\section{Cell culture and reagents}

786O, SW839, and HEK293T cell lines were purchased from the American Type Culture Collection (ATCC, Manassas, VA). Cells were cultured in DMEM media with $1 \%$ penicillin and streptomycin, containing $10 \%$ fetal bovine serum (FBS). All cells were maintained in a humidified $5 \%(\mathrm{v} / \mathrm{v}) \mathrm{CO}_{2}$ incubator at $37{ }^{\circ} \mathrm{C}$. According to ATCC's protocol, all cell lines used in the paper have been authenticated and proven to be mycoplasma and bacteriafree and were periodically re-authenticated by PCR.

\section{Western blot}

Cells were washed twice with cold PBS and lysed in cell lysis buffer and equal proteins (30-50 $\mathrm{gg}$ ) were loading, mixed, boiled, and separated on 6-12\% SDS/PAGE gel, then transferred onto PVDF membranes (Millipore, Billerica, MA). We blocked the PVDF membranes for $1 \mathrm{~h}$ via $5 \%$ skim milk and incubated with the specific primary antibodies overnight. After incubated with HRP-conjugated secondary antibodies, the PVDF membranes were visualized using the ECL system (Thermo Fisher Scientific, Rochester, NY). Primary antibodies used in the study for western blot are listed in Table S1.

\section{In vivo studies}

All experimental procedures were performed in accordance with the National Institutes of Health Guide for the Care and use of laboratory animals, conformed to the regulations 


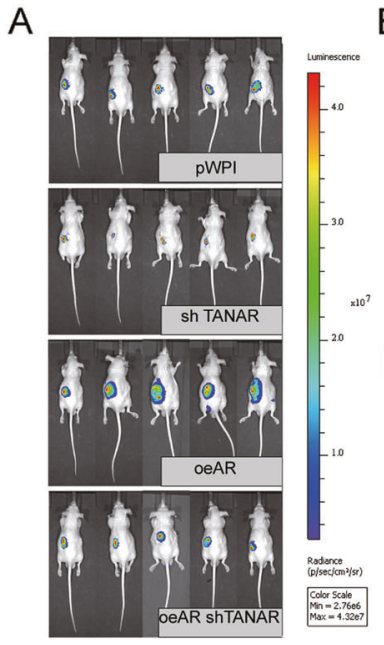

$J$
B

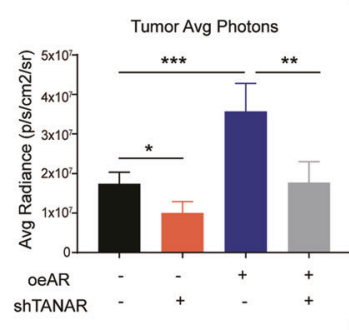

D

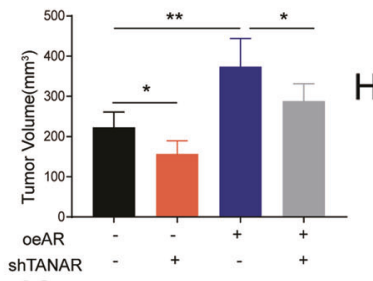

$\mathrm{K}$

C

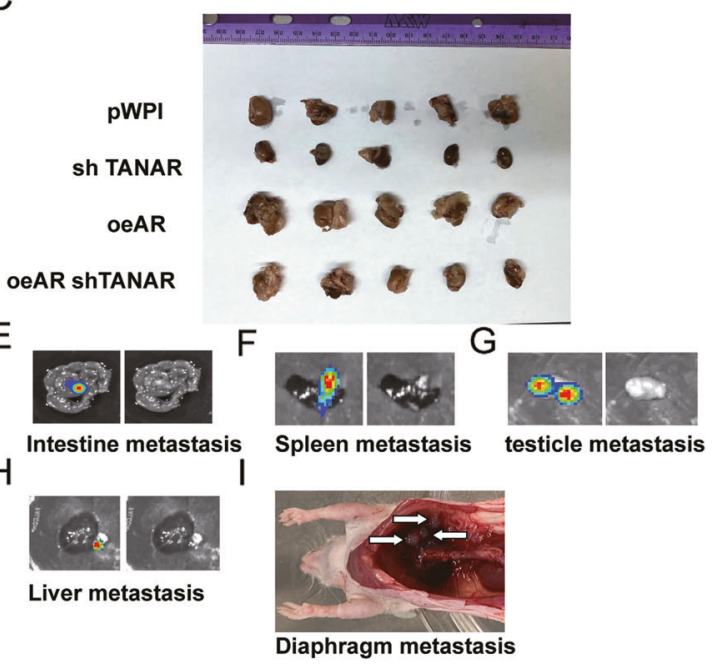

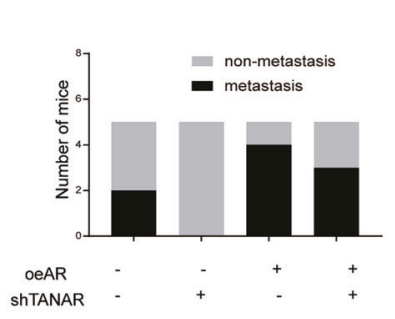

$\mathrm{L}$
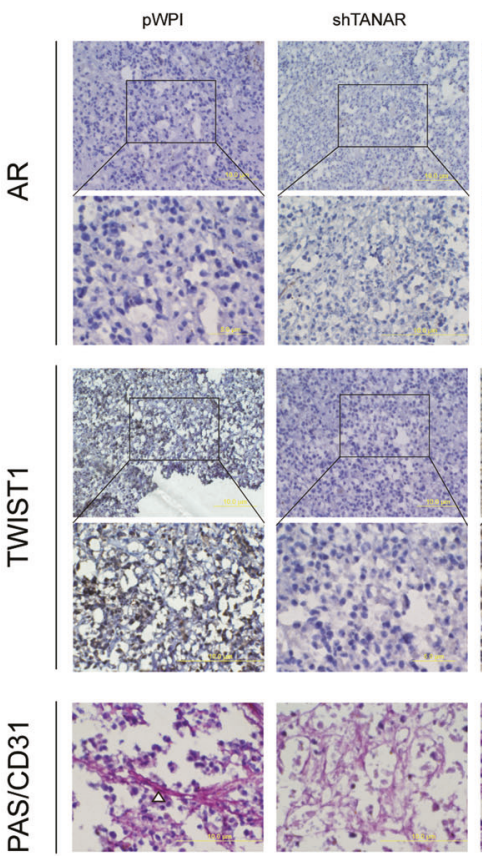

Fig. 7 Preclinical study using in vivo mouse model to test the role of AR and TANAR in ccRCC VM formation. a IVIS images of mice harboring RCC tumors after orthotopically implanting 7860 pWPI, 7860 shTANAR, 7860 oeAR, and 7860 oeAR-shTANAR cells into nude mice $(N=5)$ for 6 weeks. b Tumor average photons for ccRCC from xenograft mice described above. $\mathbf{c}$ Images of tumors are presented after mice were sacrificed and the tumor volume in each group was observed and measured (d). e-i Representative organ bioluminescent images showing metastasis from testicles, liver, intestine, spleen, and diaphragm metastasis. $\mathbf{j}$ Quantification of the metastasis in the four groups of mice. $\mathbf{k}$ Quantification of the total metastatic foci. l Representative images of IHC staining for AR, TWIST1, and VM vessel area (White triangles show PAS+/CD31-tumor cell-dependent vessels) in mice. $\mathbf{m}$ Quantification of relative IHC staining intensity for TWIST1 expression. $\mathbf{n}$ Evaluation of area percentage of VM vessels. The data are means \pm S.D. $* p<0.05, * * p<0.01$, *** $p<0.05$, and $n s$ $=$ not significant, compared with control. 
for animal experimentation, and reviewed by the Institutional Laboratory Animal Care and Use Committee of the University of Rochester Medical Center. Male athymic BALB/c nude mice (6-8 weeks old) were obtained from the Animal Production Area of the National Cancer InstituteFredrick Cancer Research and Development Center in Frederick, MD, USA. 786-O cells transfected with Scr-luc, oeAR-luc, shTANAR-luc, or oeAR+shTANAR, were injected at $1 \times 10^{6}$ cells/mouse, into the left renal capsule of 8 -week-old male athymic nude mice ( $n=5$ mice/group). After 6 weeks, mice were sacrificed, and tumors were excised and measured.

\section{Statistics}

Experiments were repeated independently at least three times with data points completed in triplicate. Results are shown as mean \pm S.D. Statistical significance was determined using the Student's $t$-test and two-way ANOVA test by SPSS 22 (IBM Corp., Armonk, NY) or GraphPad Prism 6 (GraphPad Software, Inc., La Jolla, CA). $P$ values less than 0.05 were considered statistically significant $(* P<$ $0.05, * * P<0.01$, and $* * * P<0.001)$.

\section{Data availability}

The datasets used and analyzed during the current study are available from the corresponding author on reasonable request.

Acknowledgements This work was supported by George Whipple Professorship. We thank Karen Wolf for help preparing the manuscript.

Funding This work was supported by NIH grant (CA155477).

\section{Compliance with ethical standards}

Conflict of interest The authors declare that they have no conflict of interest.

Ethics approval and consent to participate Ethics approval and consent to participateEthical consent were approved by the Committees for Ethical Review of Research involving Human Subjects at Harbin Medical University. Written informed consent was obtained from each patient prior to sample collection. The animal experiments were approved by the Use Committee for Animal Care at the University of Rochester Medical center.

Publisher's note Springer Nature remains neutral with regard to jurisdictional claims in published maps and institutional affiliations.

Open Access This article is licensed under a Creative Commons Attribution 4.0 International License, which permits use, sharing, adaptation, distribution and reproduction in any medium or format, as long as you give appropriate credit to the original author(s) and the source, provide a link to the Creative Commons license, and indicate if changes were made. The images or other third party material in this article are included in the article's Creative Commons license, unless indicated otherwise in a credit line to the material. If material is not included in the article's Creative Commons license and your intended use is not permitted by statutory regulation or exceeds the permitted use, you will need to obtain permission directly from the copyright holder. To view a copy of this license, visit http://creativecommons. org/licenses/by/4.0/.

\section{References}

1. Ferlay J, Colombet M, Soerjomataram I, Mathers C, Parkin DM, Piñeros $\mathrm{M}$, et al. Estimating the global cancer incidence and mortality in 2018: GLOBOCAN sources and methods. Int J Cancer. 2019;144:1941-53.

2. Kotecha RR, Motzer RJ, Voss MH. Towards individualized therapy for metastatic renal cell carcinoma. Nat Rev Clin Oncol. 2019;16:621-33.

3. Motzer RJ, Hutson TE, Cella D, Reeves J, Hawkins R, Guo J, et al. Pazopanib versus sunitinib in metastatic renal-cell carcinoma. N Engl J Med. 2013;369:722-31.

4. Qu L, Ding J, Chen C, Wu Z-J, Liu B, Gao Y, et al. Exosometransmitted lncARSR promotes sunitinib resistance in renal cancer by acting as a competing endogenous RNA. Cancer Cell. 2016;29:653-68.

5. Wang K, Sun Y, Guo C, Liu T, Fei X, Chang C. Androgen receptor regulates ASS1P3/miR-34a-5p/ASS1 signaling to promote renal cell carcinoma cell growth. Cell Death Dis. 2019;10:339.

6. Huang Q, Sun Y, Ma X, Gao Y, Li X, Niu Y, et al. Androgen receptor increases hematogenous metastasis yet decreases lymphatic metastasis of renal cell carcinoma. Nat Commun. 2017;8:918.

7. Lucca I, Klatte T, Fajkovic H, De Martino M, Shariat SFJNRU. Gender differences in incidence and outcomes of urothelial and kidney cancer. Nat Rev Urol. 2015;12:585.

8. Adelaiye-Ogala R, Damayanti NP, Orillion AR, Arisa S, Chintala $\mathrm{S}$, Titus MA, et al. Therapeutic targeting of sunitinib-induced AR phosphorylation in renal cell carcinoma. Cancer Res. 2018;78:2886-96.

9. Zhao H, Leppert JT, Peehl DMJPO. A protective role for androgen receptor in clear cell renal cell carcinoma based on mining TCGA data. PLoS ONE. 2016;11:e0146505.

10. Maniotis AJ, Folberg R, Hess A, Seftor EA, Gardner LMG, Pe'er $\mathrm{J}$, et al. Vascular channel formation by human melanoma cells in vivo and in vitro: vasculogenic mimicry. Am J Pathol. 1999;155:739-52.

11. Bai J, Chen JB, Qiu XF, Yeh SY, Hu LY, Zeng J, et al. Tr4 nuclear receptor promotes clear cell renal cell carcinoma $(\mathrm{Ccrcc})$ vasculogenic mimicry $(\mathrm{Vm})$ formation and metastasis via altering the Mir490-3p/vimentin signals. J Urol. 2018;199:E1200-E1200.

12. Bao ZQ, Cheng ZN, Chai DM. The expressions of CD133, ALDH1, and vasculogenic mimicry in osteosarcoma and their clinical significance. Int J Clin Exp Pathol. 2018;11:3656-63.

13. Cui YF, Liu AH, An DZ, Sun RB, Shi Y, Shi YX, et al. Claudin-4 is required for vasculogenic mimicry formation in human breast cancer cells. Oncotarget. 2015;6:11087-97.

14. Gong WC, Sun BC, Zhao XL, Zhang DF, Sun JY, Liu TJ, et al. Nodal signaling promotes vasculogenic mimicry formation in breast cancer via the $\operatorname{Smad} 2 / 3$ pathway. Oncotarget. 2016;7:70152-67.

15. Sun T, Sun BC, Zhao XL, Zhao N, Dong XY, Che N, et al. Promotion of tumor cell metastasis and vasculogenic mimicry by way of transcription coactivation by Bcl-2 and Twist1: a study of hepatocellular carcinoma. Hepatology. 2011;54:1690-706. 
16. Zhang JX, Zhang GX, Hu PP, Deng GD, Liu QQ, Qiao LL, et al. Vasculogenic mimicry is associated with increased tumorinfiltrating neutrophil and poor outcome in esophageal squamous cell carcinoma. Oncotargets Ther. 2017;10:2923-30.

17. Serova M, Tijeras-Raballand A, Dos Santos C, Martinet M, Neuzillet C, Lopez A, et al. Everolimus affects vasculogenic mimicry in renal carcinoma resistant to sunitinib. Oncotarget. 2016;7:38467-86.

18. Velez D, Tsui B, Goshia T, Chute C, Han A, Carter H, et al. 3D collagen architecture induces a conserved migratory and transcriptional response linked to vasculogenic mimicry. Nat Commun. 2017;8:1651.

19. Zhang Y, Sun B, Zhao X, Liu Z, Wang X, Yao X, et al. Clinical significances and prognostic value of cancer stem-like cells markers and vasculogenic mimicry in renal cell carcinoma. J Surg Oncol. 2013;108:414-9.

20. Engreitz JM, Ollikainen N, Guttman MJNRMCB. Long noncoding RNAs: spatial amplifiers that control nuclear structure and gene expression. Nat Rev Mol Cell Biol. 2016;17:756.

21. Flippot R, Beinse G, Boilève A, Vibert J, Malouf GG. Long noncoding RNAs in genitourinary malignancies: a whole new world. Nat Rev Urol. 2019;16:484-504.

22. Zhai W, Sun Y, Guo C, Hu G, Wang M, Zheng J, et al. LncRNASARCC suppresses renal cell carcinoma (RCC) progression via altering the androgen receptor (AR)/miRNA-143-3p signals. Cell Death Differ. 2017;24:1502.

23. Zhuang JL, Shen L, Yang L, Huang XJ, Lu Q, Cui YY, et al. TGF beta 1 promotes gemcitabine resistance through regulating the LncRNA-LET/NF90/miR-145 signaling axis in bladder cancer. Theranostics. 2017;7:3053-67.

24. Shang Z, Yu J, Sun L, Tian J, Zhu S, Zhang B, et al. LncRNA PCAT1 activates AKT and NF-kappaB signaling in castrationresistant prostate cancer by regulating the PHLPP/FKBP51/ IKKalpha complex. Nucleic Acids Res. 2019;47:4211-25.

25. Luo J, Wang K, Yeh S, Sun Y, Liang L, Xiao Y, et al. LncRNAp21 alters the antiandrogen enzalutamide-induced prostate cancer neuroendocrine differentiation via modulating the EZH2/ STAT3 signaling. Nat Commun. 2019;10:2571.

26. Franks TM, Singh G, Lykke-Andersen JJC. Upf1 ATPasedependent mRNP disassembly is required for completion of nonsense-mediated mRNA decay. Cell. 2010;143:938-50.

27. Higgins JP, Shinghal R, Gill H, Reese JH, Terris M, Cohen RJ, et al. Gene expression patterns in renal cell carcinoma assessed by complementary DNA microarray. Am J Pathol. 2003;162:925-32.

28. Xia Y, Cai XY, Fan JQ, Zhang LL, Ren JH, Li ZY, et al. The role of sema4D in vasculogenic mimicry formation in non-small cell lung cancer and the underlying mechanisms. Int $\mathrm{J}$ Cancer. 2019;144:2227-38.

29. Hendrix MJC, Seftor EA, Hess AR, Seftor REB. Vasculogenic mimicry and tumour-cell plasticity: Lessons from melanoma. Nat Rev Cancer. 2003;3:411-21.

30. Hendrix MJ, Seftor EA, Seftor RE, Chao J-T, Chien D-S, Chu YWJP, et al. Tumor cell vascular mimicry: Novel targeting opportunity in melanoma. Pharm Ther. 2016;159:83-92.

31. Lopez D, Niu G, Huber P, Carter WBJAob, biophysics. Tumorinduced upregulation of twist, snail, and slug represses the activity of the human VE-cadherin promoter. Arch Biochem Biophys. 2009;482:77-82.

32. Yang J, Zhu DM, Zhou XG, Yin N, Zhang Y, Zhang ZX, et al. HIF-2 alpha promotes the formation of vasculogenic mimicry in pancreatic cancer by regulating the binding of Twist 1 to the VEcadherin promoter. Oncotarget. 2017;8:47801-15.

33. Yochum ZA, Cades J, Wang $\mathrm{H}$, Chatterjee S, Simons BW, O'Brien JP, et al. Targeting the EMT transcription factor TWIST1 overcomes resistance to EGFR inhibitors in EGFR-mutant nonsmall-cell lung cancer. Oncogene. 2019;38:656.
34. Yochum ZA, Cades J, Mazzacurati L, Neumann NM, Khetarpal SK, Chatterjee S, et al. A first-in-class TWIST1 inhibitor with activity in oncogene-driven lung cancer. Mol Cancer Res. 2017;15:1764-76.

35. Gregory RI, Chendrimada TP, Cooch N, Shiekhattar RJC. Human RISC couples microRNA biogenesis and posttranscriptional gene silencing. Cell. 2005;123:631-40.

36. Meister G, Landthaler M, Patkaniowska A, Dorsett Y, Teng G, Tuschl TJMC. Human argonaute2 mediates RNA cleavage targeted by miRNAs and siRNAs. Mol Cell. 2004;15:185-97.

37. Cao L, Zhang P, Li J, Wu MJELAST. a c-Myc-inducible long noncoding RNA, cooperates with CNBP to promote CCND1 mRNA stability in human cells. Elife. 2017;6:e30433.

38. Knoll M, Lodish HF, Sun LJNRE. Long non-coding RNAs as regulators of the endocrine system. Nat Rev Endocrinol. 2015;11:151.

39. Wang C, Yang Y, Zhang G, Li J, Wu X, Ma X, et al. Long noncoding RNA EMS connects c-Myc to cell cycle control and tumorigenesis. Proc Natl Acad Sci USA. 2019;116:14620-9.

40. Gong C, Maquat LEJN. IncRNAs transactivate STAU1-mediated mRNA decay by duplexing with $3^{\prime}$ UTRs via Alu elements. Nature. 2011;470:284.

41. Zünd D, Gruber AR, Zavolan M, Mühlemann O. Translationdependent displacement of UPF1 from coding sequences causes its enrichment in 3' UTRs. Nat Struct Mol Biol. 2013;20:936-43.

42. Melero R, Hug N, López-Perrote A, Yamashita A, Cáceres JF, Llorca OJNC. The RNA helicase DHX34 functions as a scaffold for SMG1-mediated UPF1 phosphorylation. Nat Commun. 2016;7:10585.

43. Vartanian AA, Stepanova EV, Gutorov SL, Solomko E, Grigorieva IN, Sokolova IN, et al. Prognostic significance of periodic acid-Schiff-positive patterns in clear cell renal cell carcinoma. Can J Urol. 2009;16:4726-32.

44. Zhang Y, Sun B, Zhao X, Liu Z, Wang X, Yao X, et al. Clinical significances and prognostic value of cancer stem-like cells markers and vasculogenic mimicry in renal cell carcinoma. J Surg Oncol. 2013;108:414-9.

45. Khatiwada P, Kannan A, Malla M, Dreier M, Shemshedini L. Androgen up-regulation of Twist1 gene expression is mediated by ETV1. PeerJ. 2020;8:e8921.

46. Wang L, Lin L, Chen X, Sun L, Liao YL, Huang N, et al. Metastasis-associated in colon cancer-1 promotes vasculogenic mimicry in gastric cancer by upregulating TWIST1/2. Oncotarget. 2015;6:11492-506.

47. Meng J, Chen S, Lei YY, Han JX, Zhong WL, Wang XR, et al. Hsp90 beta promotes aggressive vasculogenic mimicry via epithelial-mesenchymal transition in hepatocellular carcinoma. Oncogene. 2019;38:228-43.

48. Rasti A, Madjd Z, Abolhasani M, Mehrazma M, Janani L, Zanjani LS, et al. Cytoplasmic expression of Twist1, an EMT-related transcription factor, is associated with higher grades renal cell carcinomas and worse progression-free survival in clear cell renal cell carcinoma. Clin Exp Med. 2018;18:177-90.

49. Delgado-Bellido D, Fernandez-Cortes M, Rodriguez MI, SerranoSaenz S, Carracedo A, Garcia-Diaz A, et al. VE-cadherin promotes vasculogenic mimicry by modulating kaiso-dependent gene expression. Cell Death Differ. 2019;26:348-61.

50. Xiao T, Zhong WL, Zhao JM, Qian BX, Liu HJ, Chen S, et al. Polyphyllin I suppresses the formation of vasculogenic mimicry via Twist1/VE-cadherin pathway. Cell Death Dis. 2018;9:906.

51. Guo JQ, Cai H, Liu XB, Zheng J, Liu YH, Gong W, et al. Long non-coding RNA LINC00339 stimulates glioma vasculogenic mimicry formation by regulating the miR-539-5p/TWIST1/MMPs axis. Mol Ther-Nucl Acids. 2018;10:170-86.

52. Tao W, Sun WM, Zhu HL, Zhang JY. Knockdown of long noncoding RNA TP73-AS1 suppresses triple negative breast cancer 
cell vasculogenic mimicry by targeting miR-490-3p/TWIST1 axis. Biochem Bioph Res Commun. 2018;504:629-34.

53. Li R-H, Chen M, Liu J, Shao C-C, Guo C-P, Wei X-L, et al. Long noncoding RNA ATB promotes the epithelial-mesenchymal transition by upregulating the miR-200c/Twist 1 axe and predicts poor prognosis in breast cancer. Cell Death Dis. 2018;9:1171.

54. Zerbino DR, Achuthan P, Akanni W, Amode MR, Barrell D, Bhai J, et al. Ensembl 2018. Nucleic Acids Res. 2018;46: D754-D761.

55. Hu Z, Yau C, Ahmed AAJNC. A pan-cancer genome-wide analysis reveals tumour dependencies by induction of nonsensemediated decay. Nat Commun. 2017;8:15943.

56. Karam R, Carvalho J, Bruno I, Graziadio C, Senz J, Huntsman D, et al. The NMD mRNA surveillance pathway downregulates aberrant E-cadherin transcripts in gastric cancer cells and in CDH1 mutation carriers. Oncogene. 2008;27:4255.

57. Popp MW, Maquat LEJCoig, development. Nonsense-mediated mRNA decay and cancer. Curr Opin Genet Dev. 2018;48:44-50.

58. Han S, Cao D, Sha J, Zhu X, Chen D. LncRNA ZFPM2-AS1 promotes lung adenocarcinoma progression by interacting with UPF1 to destabilize ZFPM2. Mol Oncol. 2020;14:1074-88.

59. Xie X, Lin J, Liu J, Huang M, Zhong Y, Liang B, et al. A novel lncRNA NR4A1AS upregulates orphan nuclear receptor NR4A1 expression by blocking UPF1-mediated mRNA destabilization in colorectal cancer. Clin Sci. 2019;133:1457-73.

60. Imamachi N, Salam KA, Suzuki Y, Akimitsu NJGR. A GC-rich sequence feature in the $3^{\prime}$ UTR directs UPF1-dependent mRNA decay in mammalian cells. Genome Res. 2017;27:407-18. 